\title{
The outcome of in- and out-hospital cardiopulmonary arrest in the older population: a scoping review
}

\author{
Rina Zanders ${ }^{1} \mathbb{D} \cdot{\text { Patrick } \text { Druwé }^{2} \cdot \text { Nele Van Den Noortgate }}^{3} \cdot$ Ruth Piers $^{3}$
}

Received: 8 September 2020 / Accepted: 16 January 2021 / Published online: 8 March 2021

(c) European Geriatric Medicine Society 2021

\section{Key summary points}

Aim We aimed to collect the available evidence on outcome regarding survival and quality of life after CPR following both IHCA and OHCA in the older population.

Findings Hospital survival rates following IHCA and OHCA in the older population improved in the recent decade, though do not exceed $28.5 \%$ and $11.1 \%$, respectively. The effect of age on outcome remains controversial and age should not be used as the sole decision criterium whether to initiate CPR.

Message Future research should study frailty and resilience as an independent predictor regardless of age, and add broader, extensive QoL measures as outcome variables.

\begin{abstract}
Purpose We aimed to collect the available evidence on outcome regarding survival and quality of life after cardiopulmonary resuscitation (CPR) following both in-hospital cardiac arrest (IHCA) and out-of-hospital cardiac arrest (OHCA) in the older population.

Methods A scoping review was performed studying published reviews after 2008, focusing on outcome of CPR in patients aged $\geq 70$ years following IHCA and OHCA. In addition, 11 (IHCA) and 19 (OHCA) eligible studies published after the 2 included reviews were analyzed regarding: return of spontaneous circulation, survival until hospital discharge, long-term survival, neurological outcome, discharge location or other measurements for quality of life (QoL).

Results The survival until hospital discharge ranged between 11.6 and $28.5 \%$ for IHCA and $0-11.1 \%$ for OHCA, and declined with increasing age. The same trend was seen regarding 1-year survival rates with $5.7-25.0 \%$ and $0-10 \%$ following IHCA and OHCA, respectively. A good neurological outcome defined as a Cerebral Performance Category (CPC) 1-2 was found in 11.5-23.6\% (IHCA) and up to 10.5\% (OHCA) of all patients. However, the proportion of CPC 1-2 among patients surviving until hospital discharge was 82-93\% (IHCA) and 77-91.6\% (OHCA). Few studies included other QoL measures as an outcome variable. Other risk factors aside from age were identified, including nursing home residency, comorbidity, non-shockable rhythm, non-witnessed arrest. The level of frailty was not studied as a predictor of arrest outcome in the included studies.

Conclusions Hospital survival rates following IHCA and OHCA in the older population improved in the recent decade, though do not exceed $28.5 \%$ and $11.1 \%$, respectively. The effect of age on outcome remains controversial and age should not be used as the sole decision criterium whether to initiate CPR. Future research should study frailty and resilience as an independent predictor regardless of age, and add broader, extensive QoL measures as outcome variables.
\end{abstract}

Keywords Age $\cdot$ CPR $\cdot$ Functional state $\cdot$ Neurological outcome $\cdot$ Quality of life $\cdot$ Survival

Rina Zanders

rina.zanders@ugent.be

1 Faculty of Medicine and Health Sciences, Ghent University Hospital, Ghent, Belgium
2 Department of Intensive Care Medicine, Ghent University Hospital, Ghent, Belgium

3 Department of Geriatrics, Ghent University Hospital, Ghent, Belgium 


\section{Introduction}

A cardiopulmonary arrest can be defined as the cessation of cardiac mechanical activity as confirmed by the absence of signs of circulation [1]. When this condition occurs in a hospital setting, it is referred to as an in-hospital cardiac arrest (IHCA). An out-of-hospital cardiac arrest (OHCA) takes place in prehospital environments.

Cardiac arrests are more frequently seen in people with advanced age. A study in Japan reported that patients aged 65 years and older accounted for more than $80 \%$ of all patients with OHCA [2]. In view of the rapid, worldwide expansion of this older section of the population, a higher rate of cardiac arrests can be expected [3].

Cardiopulmonary resuscitation (CPR) can be lifesaving for persons with cardiopulmonary arrest. However, patients who survive the initial resuscitation are at risk of anoxic brain damage $[4,5]$. In addition, significant emotional disorders such as anxiety, depression and posttraumatic stress disorder (PTSD) are frequent in those who survive [6]. Therefore, in some cases, the use of CPR may lead to prolongation of the dying phase and suffering without adding to quality of life.

As such, it is important that resuscitation attempts occur in accordance with the preferences of the well-informed patient [7-9]. The driving force for their decision regarding resuscitation is quality of life post-resuscitation. Many patients are unrealistically optimistic about the results of CPR and thus make uninformed choices. Relevant and correct information, once provided, influences the final decision considerably [10]. It is up to the healthcare professional to explain the success rate and possible harmful effects of CPR to the patient and their family [11].

To provide accurate information and make the optimal decision for each individual, it is important for healthcare professionals to identify those subgroups with good chances of a satisfactory post-arrest quality of life [12, 13].

In this scoping review, we aimed to collect all available and recent evidence on outcome regarding survival and quality of life after CPR following both IHCA and $\mathrm{OHCA}$ in the older population, including indicators of poor prognosis.

\section{Methodology}

\section{Search strategy}

A search was conducted to find the most recent systematic reviews concerning survival and quality of life following IHCA and OHCA in patients 70 years or older.
Subsequently, a search was conducted to find all primary studies published after these systematic reviews to acquire the most recent available evidence. This was done separately for IHCA and OHCA, using analogous search entries.

Review selection The MEDLINE, EMBASE, PubMed and Google Scholar databases were electronically searched in October 2018 to find reviews concerning CPR outcomes in the older population. The search strategy cross-referenced 'elderly', 'resuscitation' and 'functional outcome' using appropriate synonyms, medical subject headings (MeSH), keywords and filters (Appendix 1 in ESM). The references from relevant reviews were also scanned for additional studies. The remaining titles were scanned to exclude other study types (such as randomized controlled trials, observational studies, editorials, case reports, caseseries, and narrative reviews), duplicates and articles in a language different from Dutch or English or of which no free full text could be obtained.

Other reasons for exclusion were reviews that lacked relevant outcomes, focused on the effect of a specific treatment or specifically investigated the association with a pathology (such as malignancies or pneumonia). Reviews with irrelevant study populations (too young) or conditions (such as victims of avalanches) were also excluded (Fig. 1). Indistinct cases were discussed and resolved by consensus with RP, NVDN and PD.

Two systematic reviews were found using the search strategy mentioned above, concerning IHCA and OHCA, respectively [14, 15].

Primary study selection To find complementary primary studies published after these systematic reviews, a search was conducted by cross-referencing 'elderly', 'resuscitation', 'functional outcome' and 'in-hospital' or 'out-of-hospital', using appropriate medical subject headings (MeSH), keywords and filters in MEDLINE, EMBASE and PubMed to find observational studies and RCTs (Appendix 2 in ESM). The search period for the primary studies was determined by the end of the search period of the two included reviews: November 2012 to October 2018 concerning IHCA, and from May 2011 until October 2018 concerning OHCA. Older publication dates, unrelated articles, duplicates and articles in a language different from Dutch or English were excluded. Other reasons for exclusion were articles that focused on irrelevant outcomes, populations or contexts; comparisons of scores, guidelines, measurement tools or models, and the effect of a specific pathology or treatment on outcome (Figs. 2, 3). In total, 11 articles were included concerning IHCA [16-26] and 19 articles concerning OHCA [27-45]. 


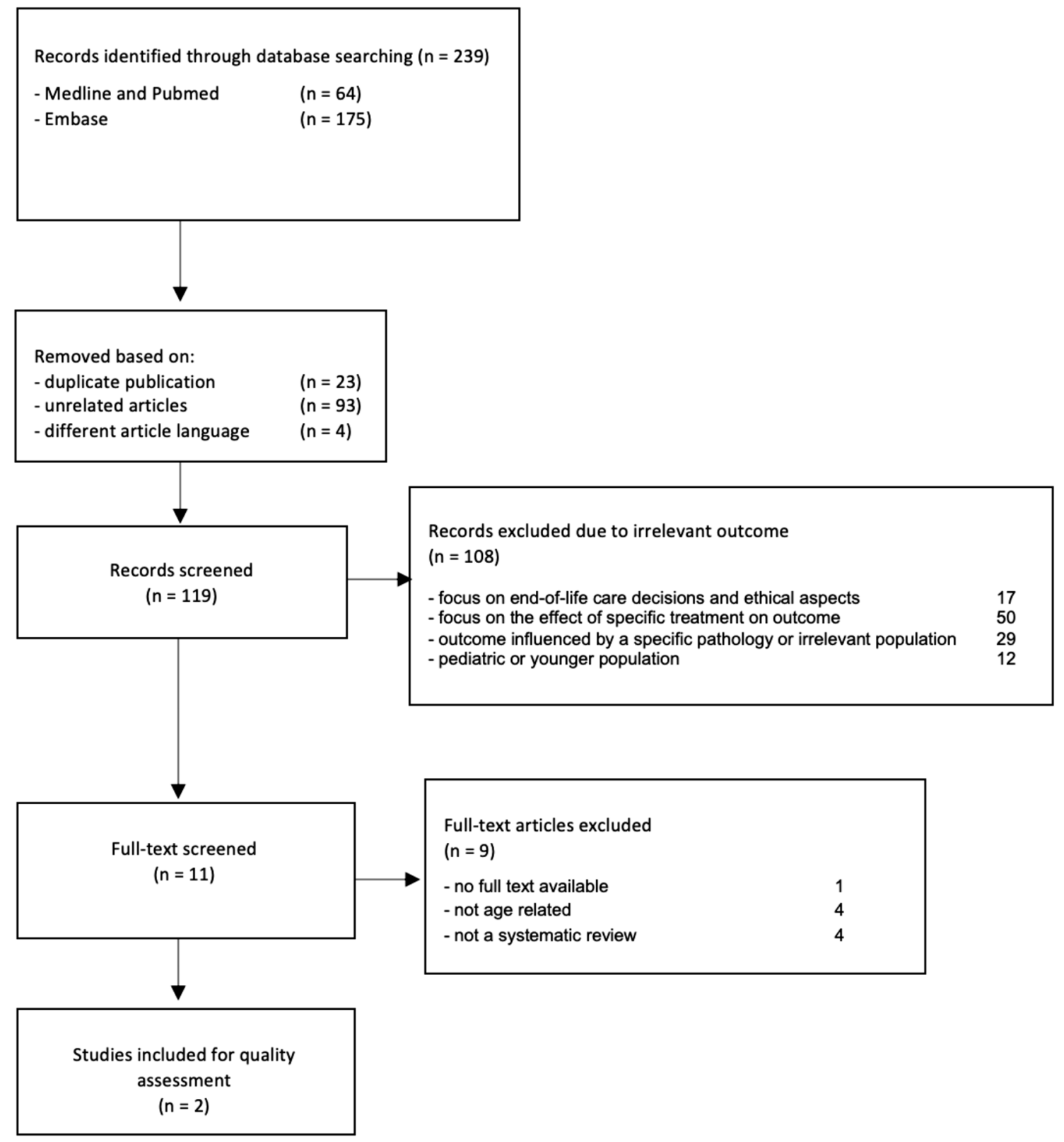

Fig. 1 Search and study selection: systematic reviews

\section{Quality assessment}

For quality assessment of the reviews, the AMSTAR measurement tool was applied. This checklist consists of 11 items. A review was considered to be of low, moderate or high quality when, respectively, $\leq 5,6-8$, or $\geq 9$ of the requirements were fulfilled. Both reviews proved to be of moderate quality (Appendix 3 in ESM).

The STROBE checklist was used to assess the quality of the primary studies. A review was considered to be of low, moderate or high quality when, respectively, $\leq 10,11-16$, or $\geq 17$ of the requirements were fulfilled. For the primary articles concerning IHCA and OHCA, all included studies proved to be of high quality after assessment (Appendix 4 in ESM). In 7 IHCA articles and 14 OHCA articles, Utsteinstyle guidelines were used to report the data.

\section{Data extraction}

Data extraction was performed by RZ and subsequently verified by RP, NVDN and PD. These data concerned: author, place and research period, study design, sample size, sample characteristics, study characteristics and outcomes of interest. We collected both unadjusted 


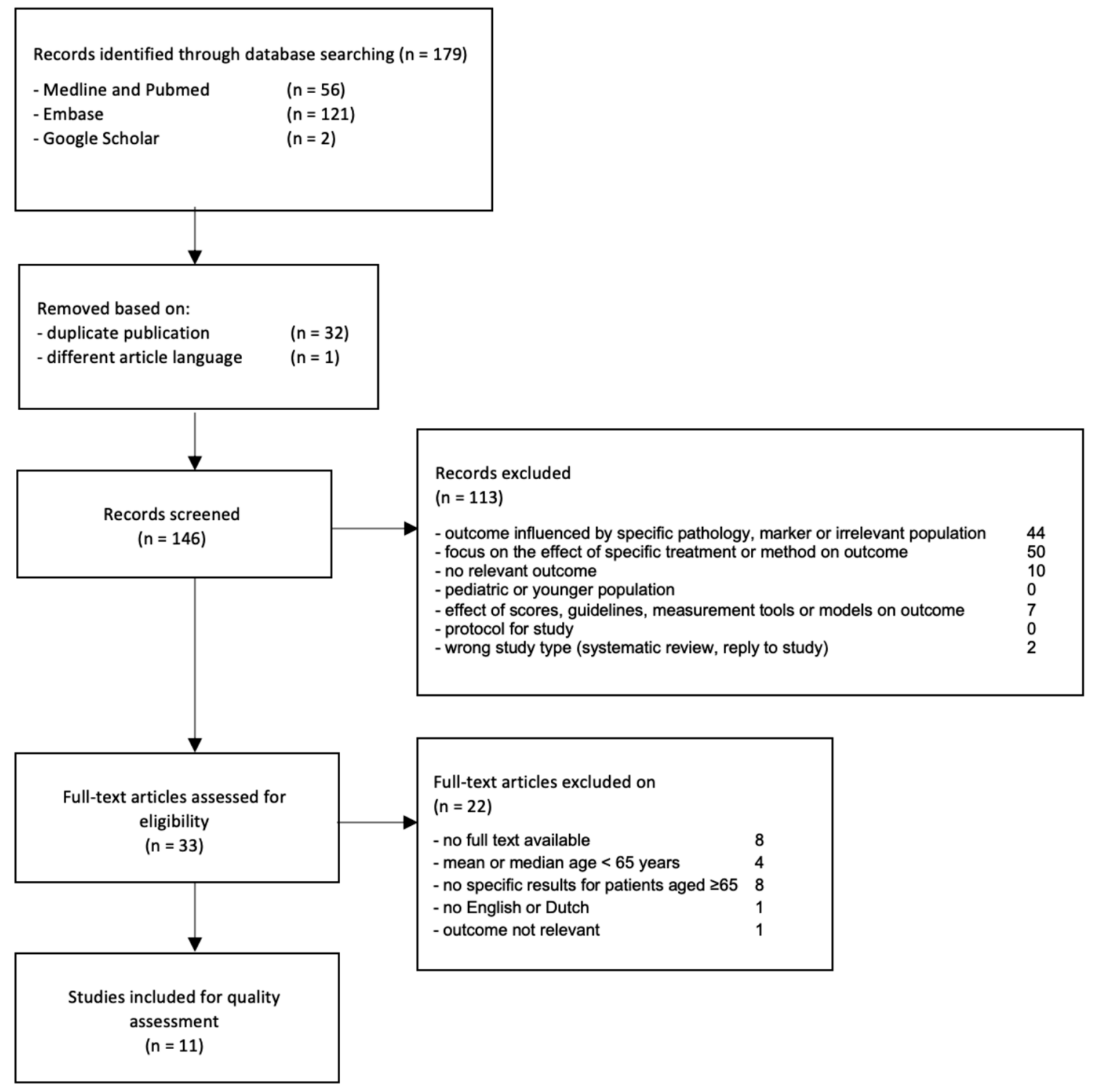

Fig. 2 Search and study selection: primary studies IHCA

and adjusted data. Outcomes were chosen a priori, and consisted of: return of spontaneous circulation (ROSC), survival until hospital discharge, long-term survival ( $\geq 6$ months following the event), discharge location and other quality of life measurements. These outcomes were structured and presented separately for the IHCA review (Table 1), the OHCA review (Table 2), the primary IHCA articles (Table 3) and the primary OHCA articles (Table 4), and additionally according to age (Table 5).

Secondary variables concerning the condition and location of the arrest such as initial cardiac rhythm, type of ward, witnessed event, bystander-initiated CPR and emergency medical services (EMS) response time were reported when registered specifically for the older population. Risk factors positively or negatively associated with survival or quality of life outcomes were also documented.

Post-resuscitation neurological and functional state were mostly analyzed using the Cerebral Performance Category scale (CPC scale) [46]. This measurement tool uses a score of 1-5 for the categories: 1: "good cerebral performance"; 2 : "moderate cerebral disability"; 3: "severe cerebral disability"; 4: "coma or vegetative state" and 5: "dead or brain death" [47]. In this review, scores of 1 or 2 are considered to be good neurological outcomes. 


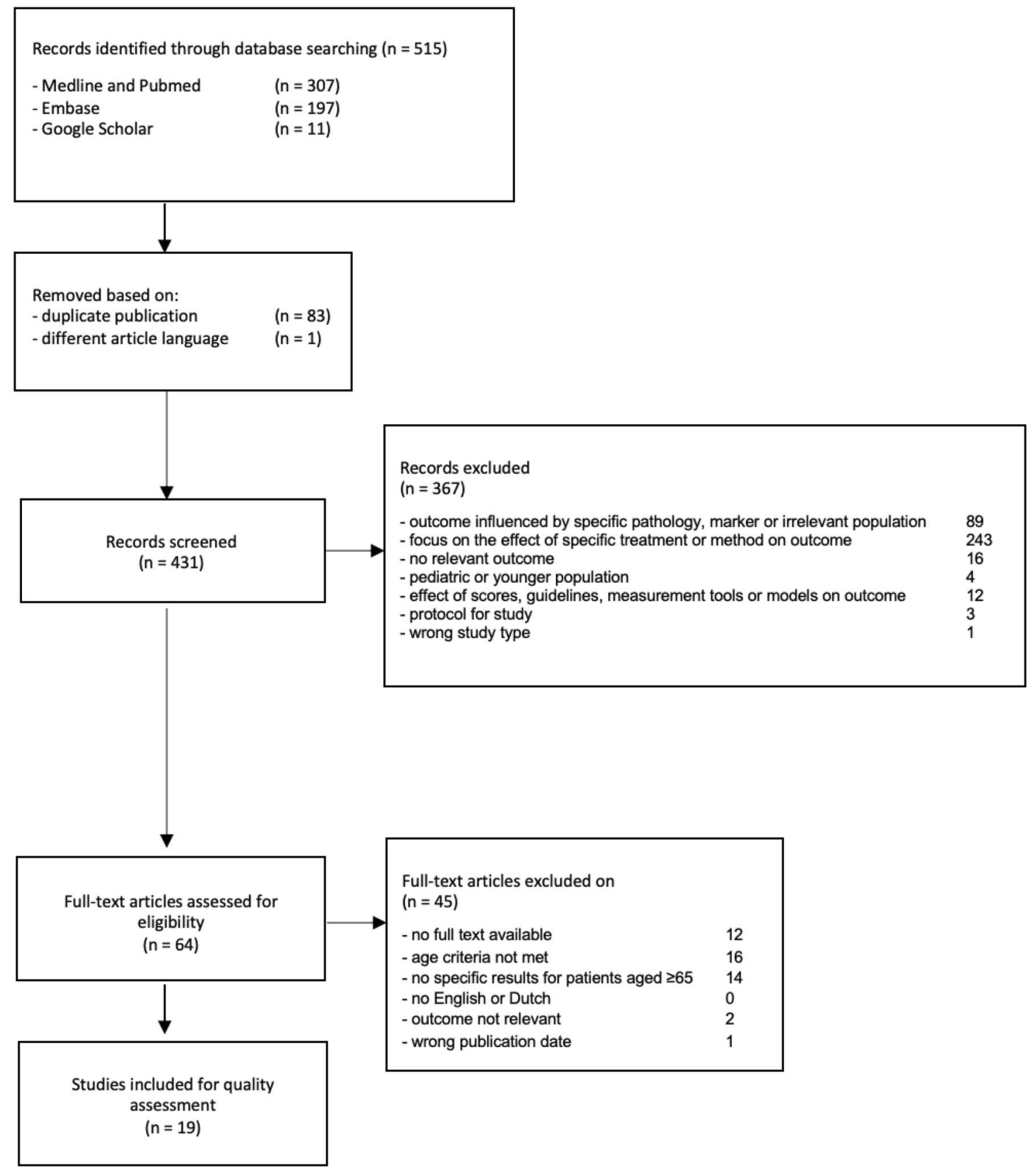

Fig. 3 Search and study selection: primary studies OHCA

\section{Results}

\section{Survival rates}

The systematic review concerning IHCA consisted of 29 studies. An overall ROSC was found in $38.6 \%$ of the resuscitated patients. Overall survival rates were lowest in the category of 90 years and older (11.6\%), followed by octogenarians $(15.4 \%)$, and highest in patients aged 70-79 years (18.7\%). Long-term survival (6 months to 1 year) varied between 5.7 and $20.9 \%$ concerning patients aged 70 years and older.

In the complementary IHCA studies, overall survival until hospital discharge was systematically higher and varied 


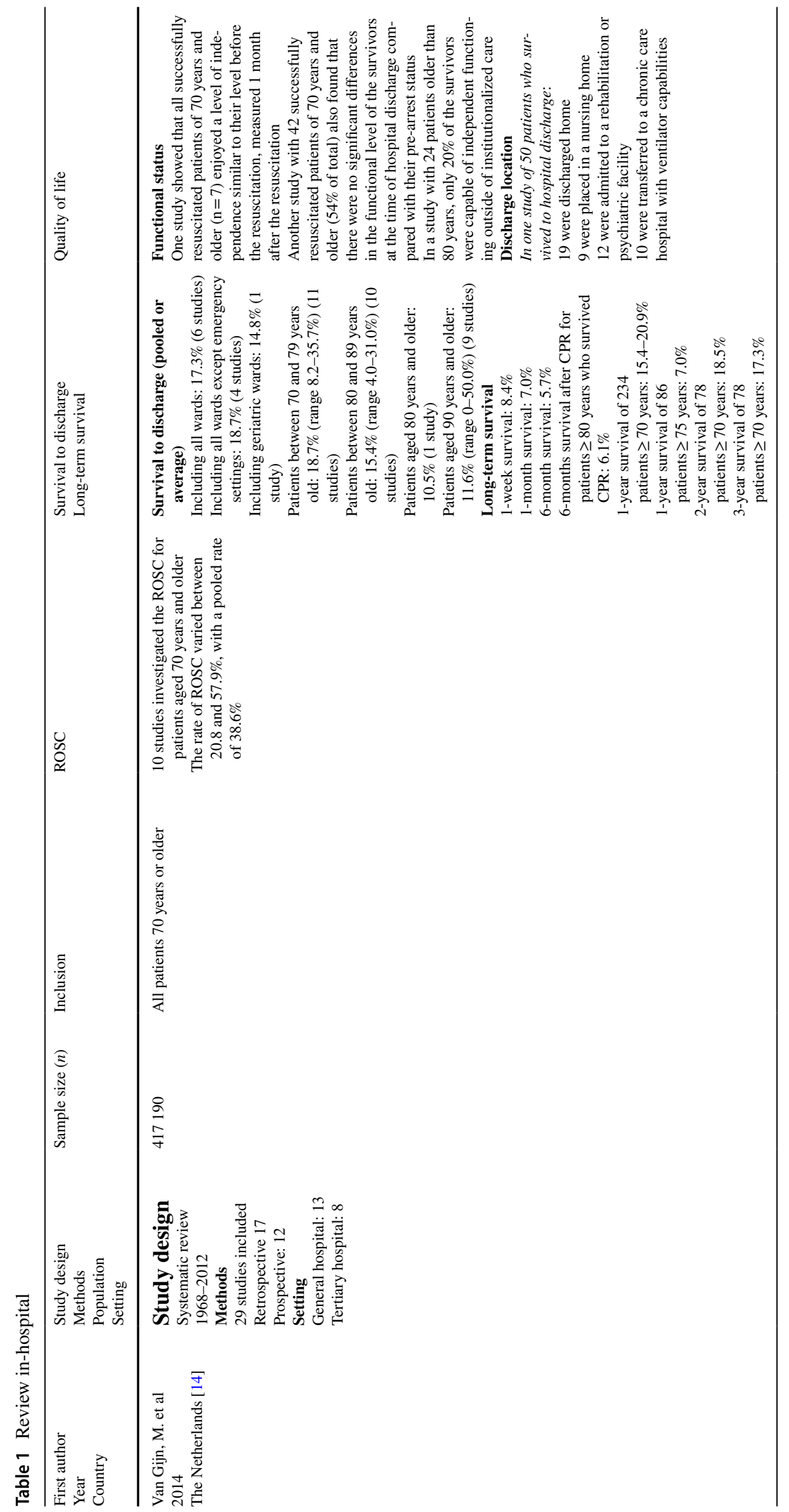




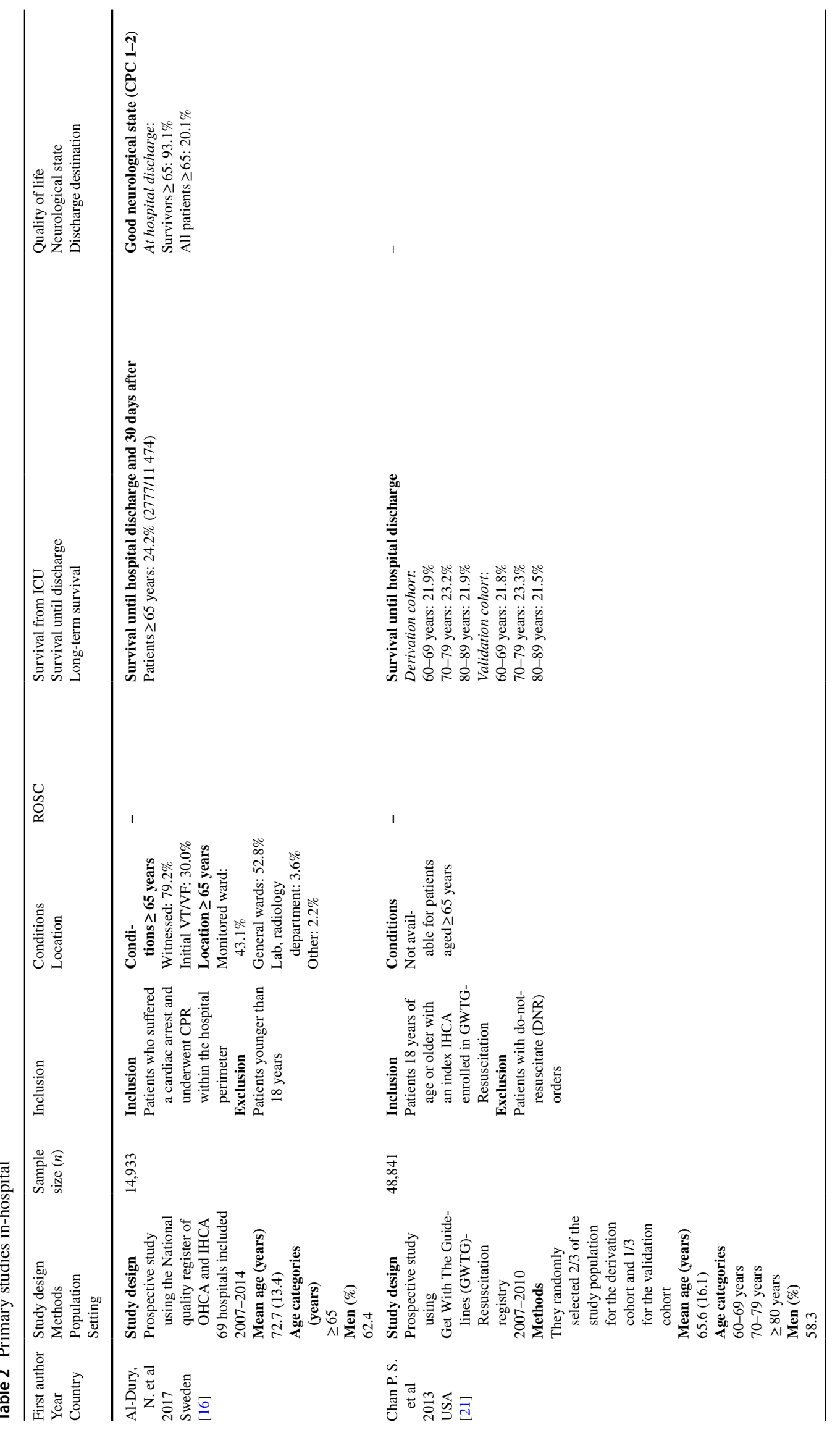




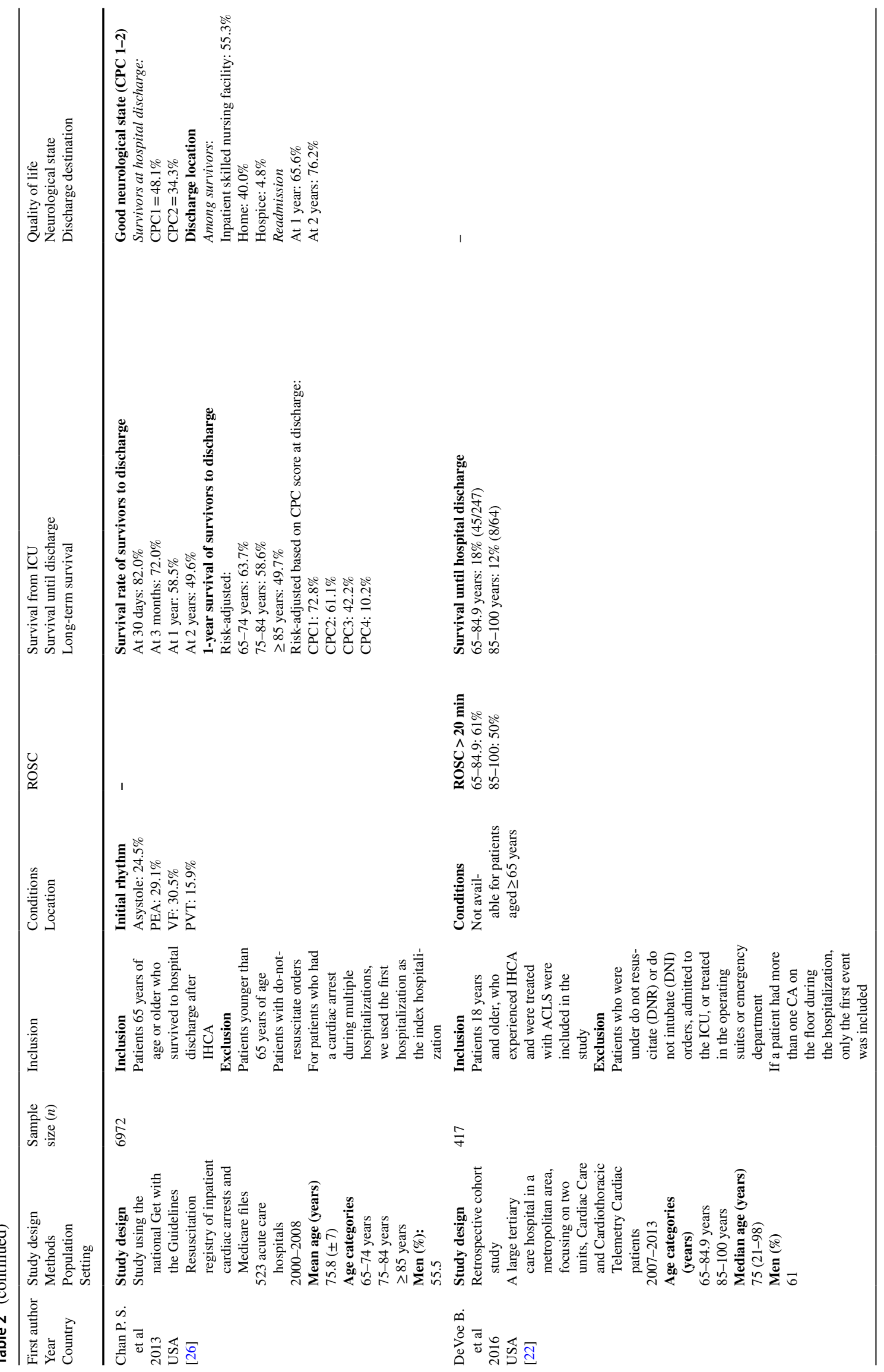




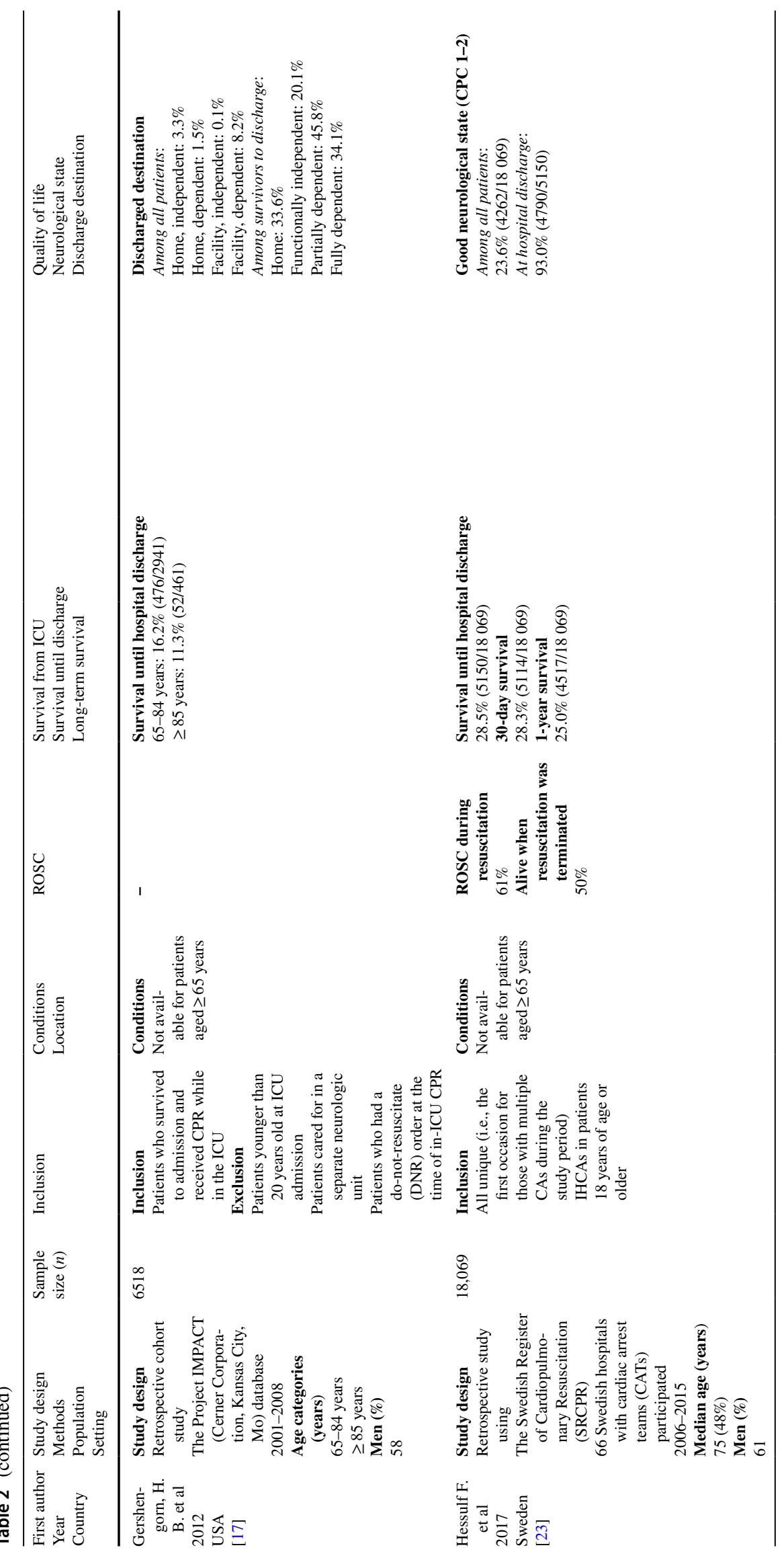




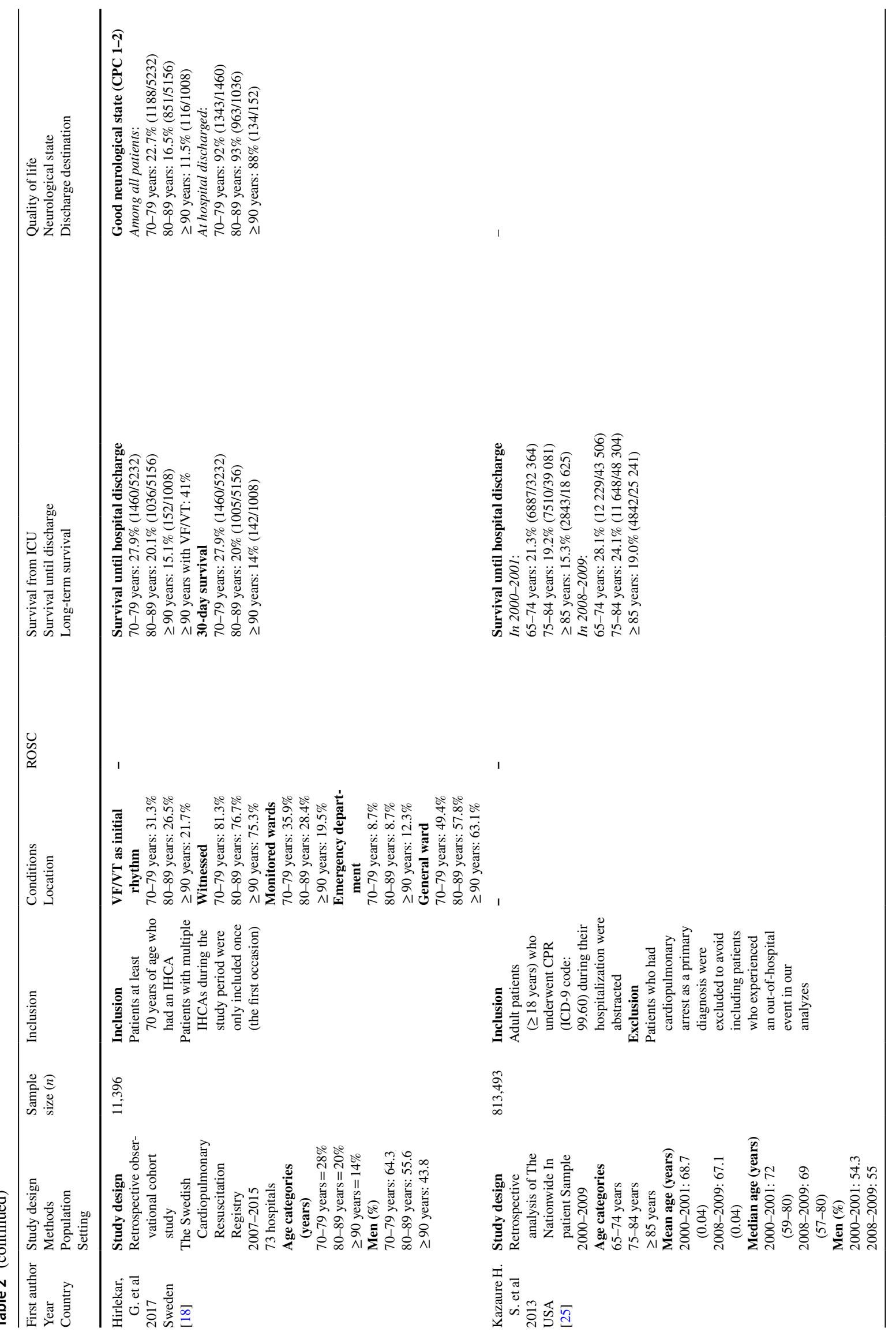




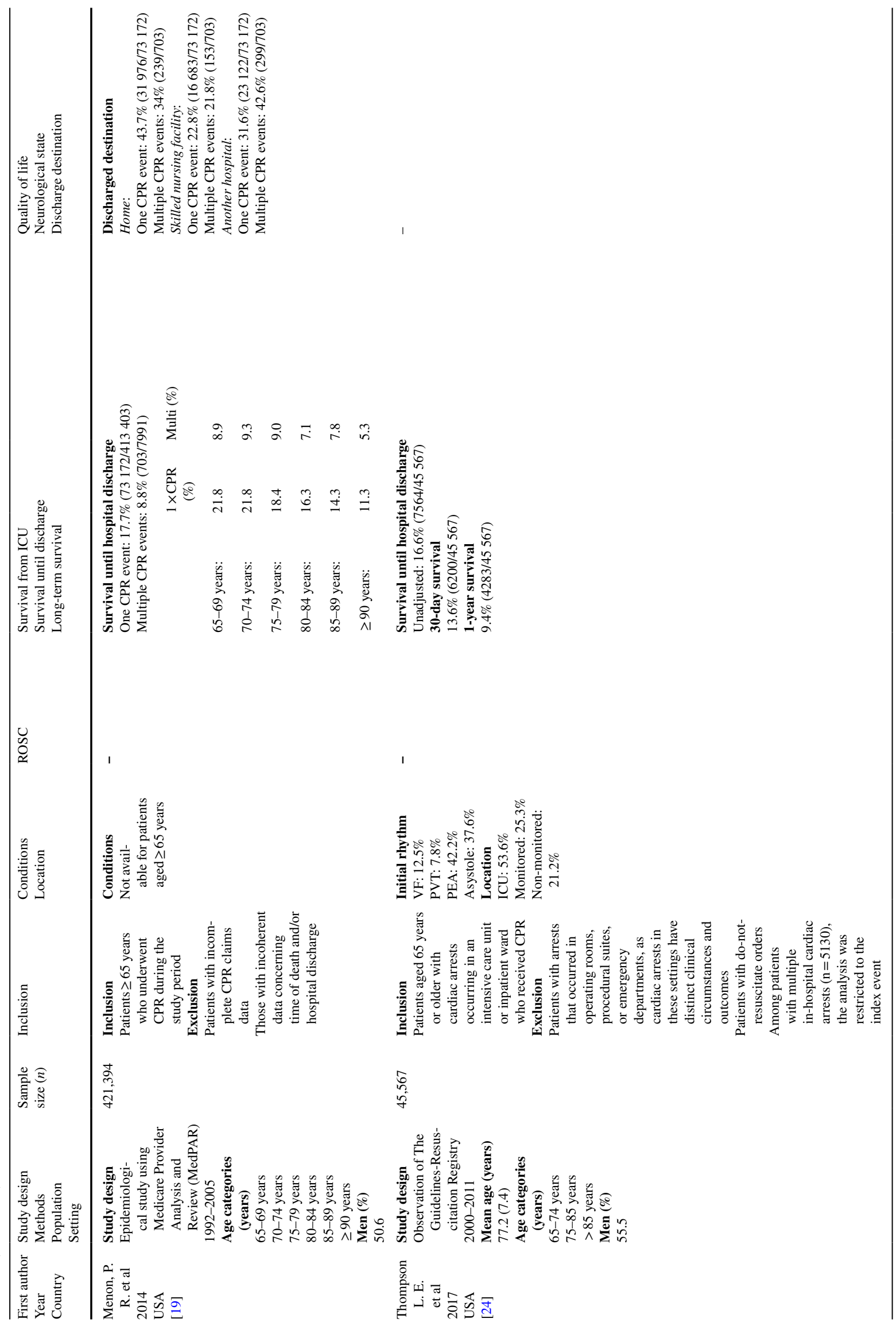




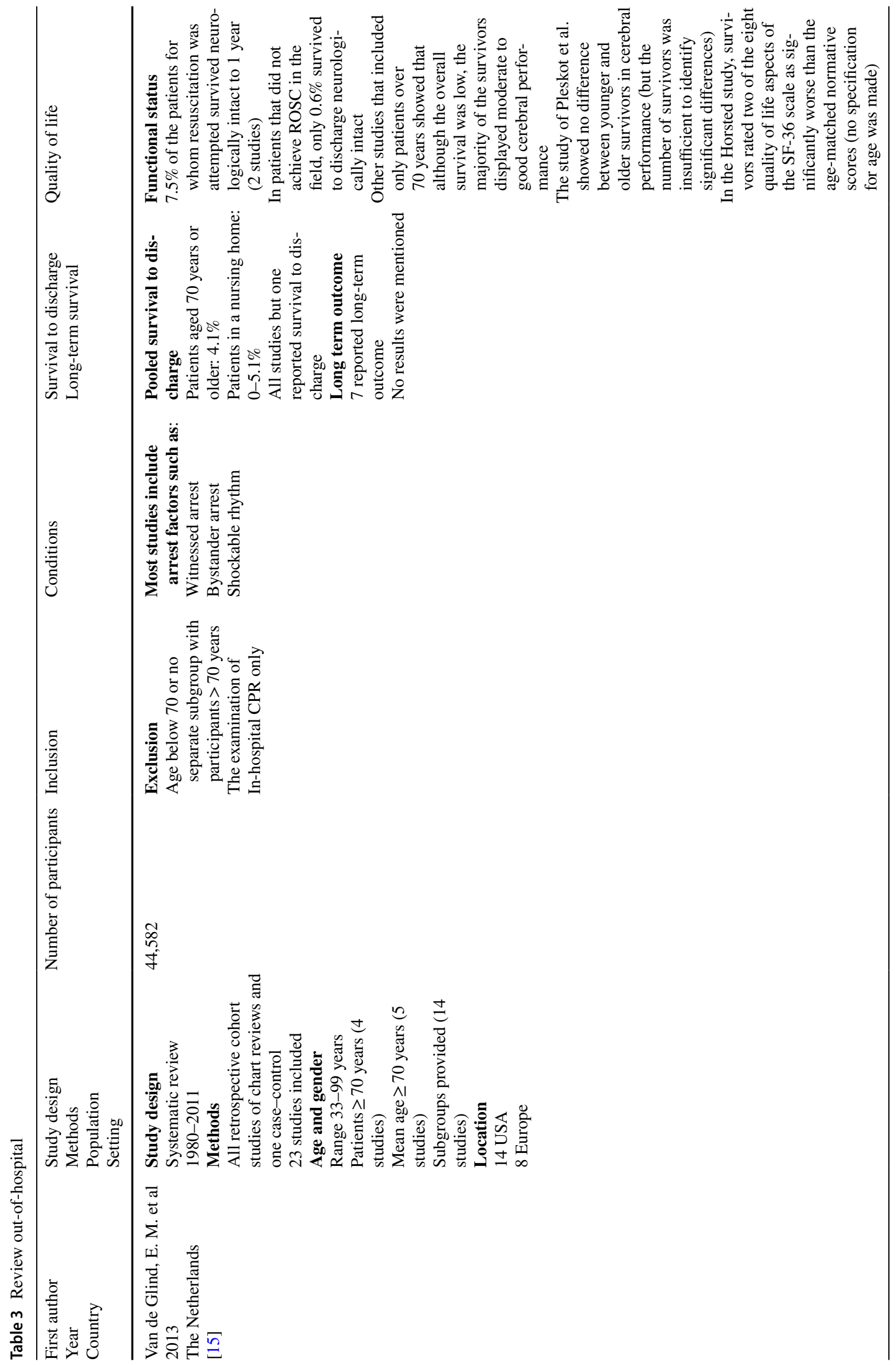




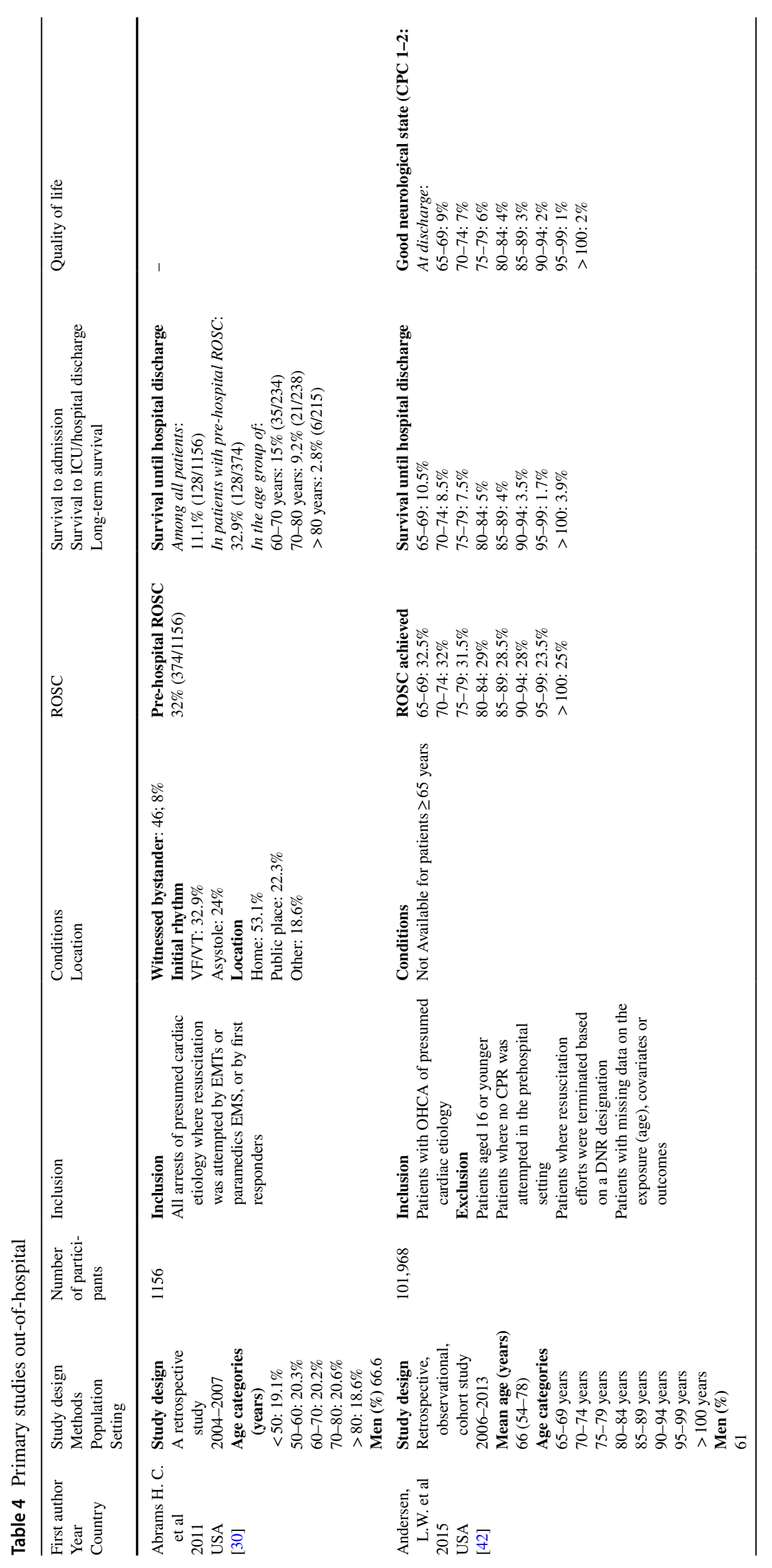




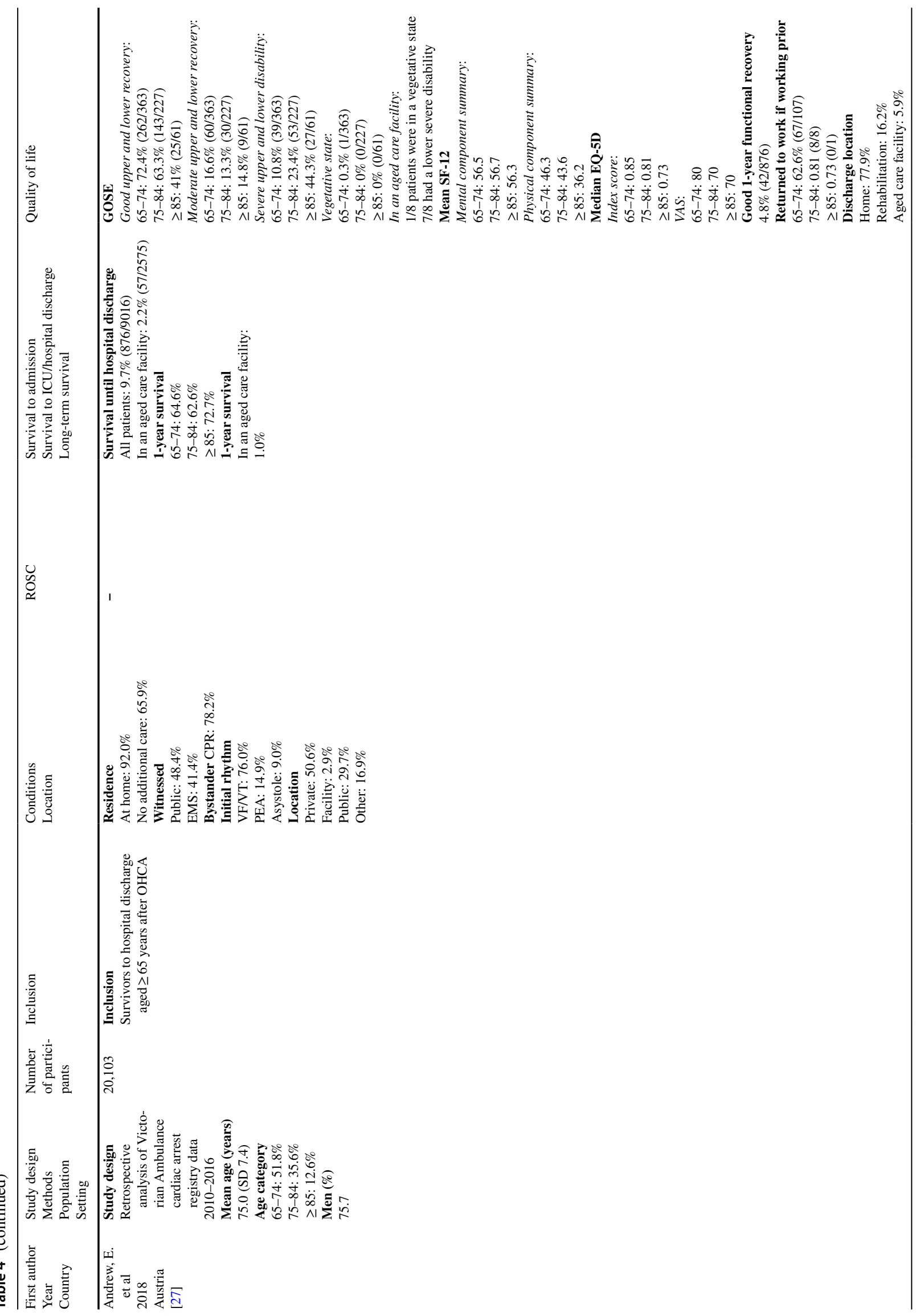




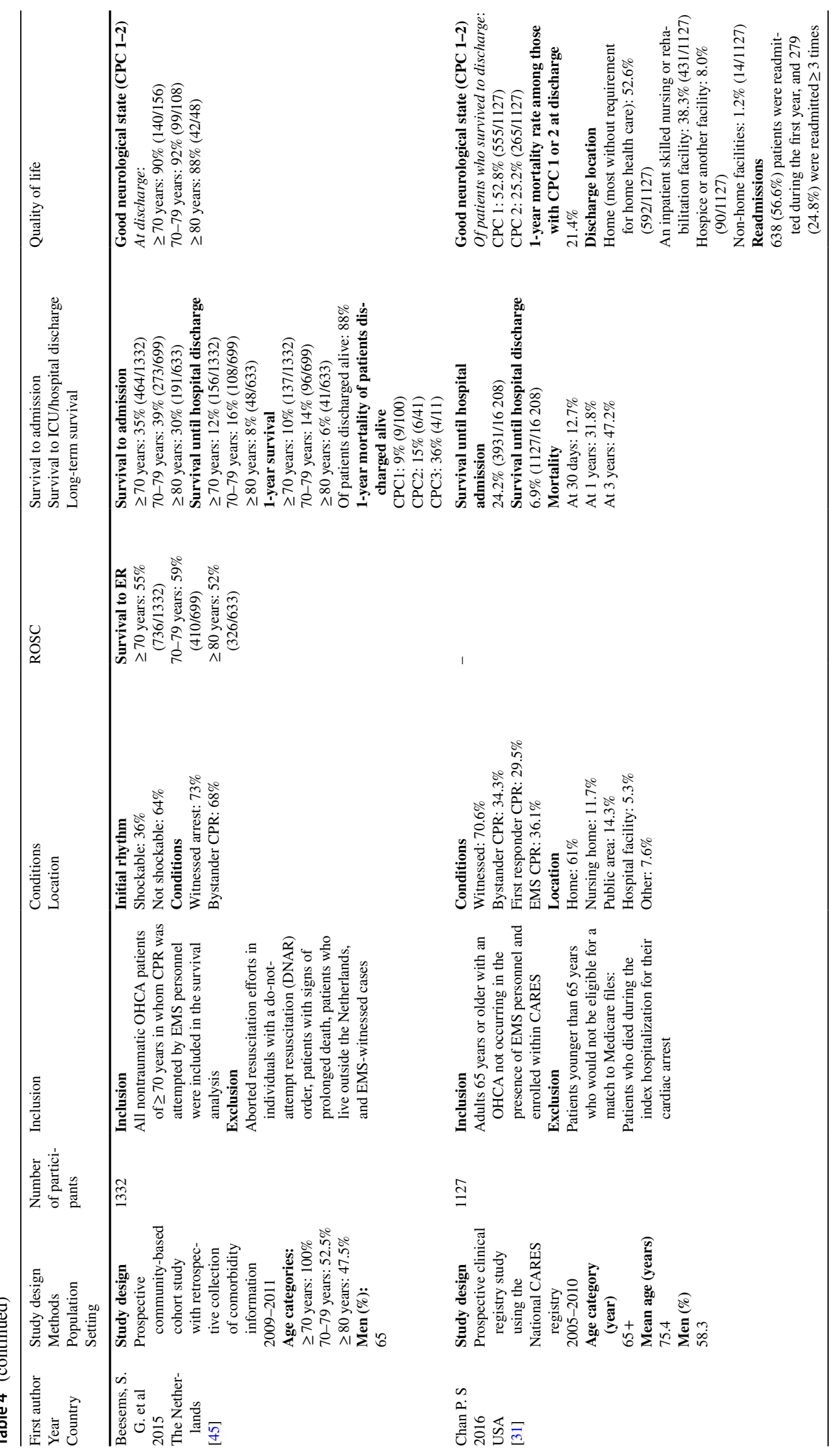




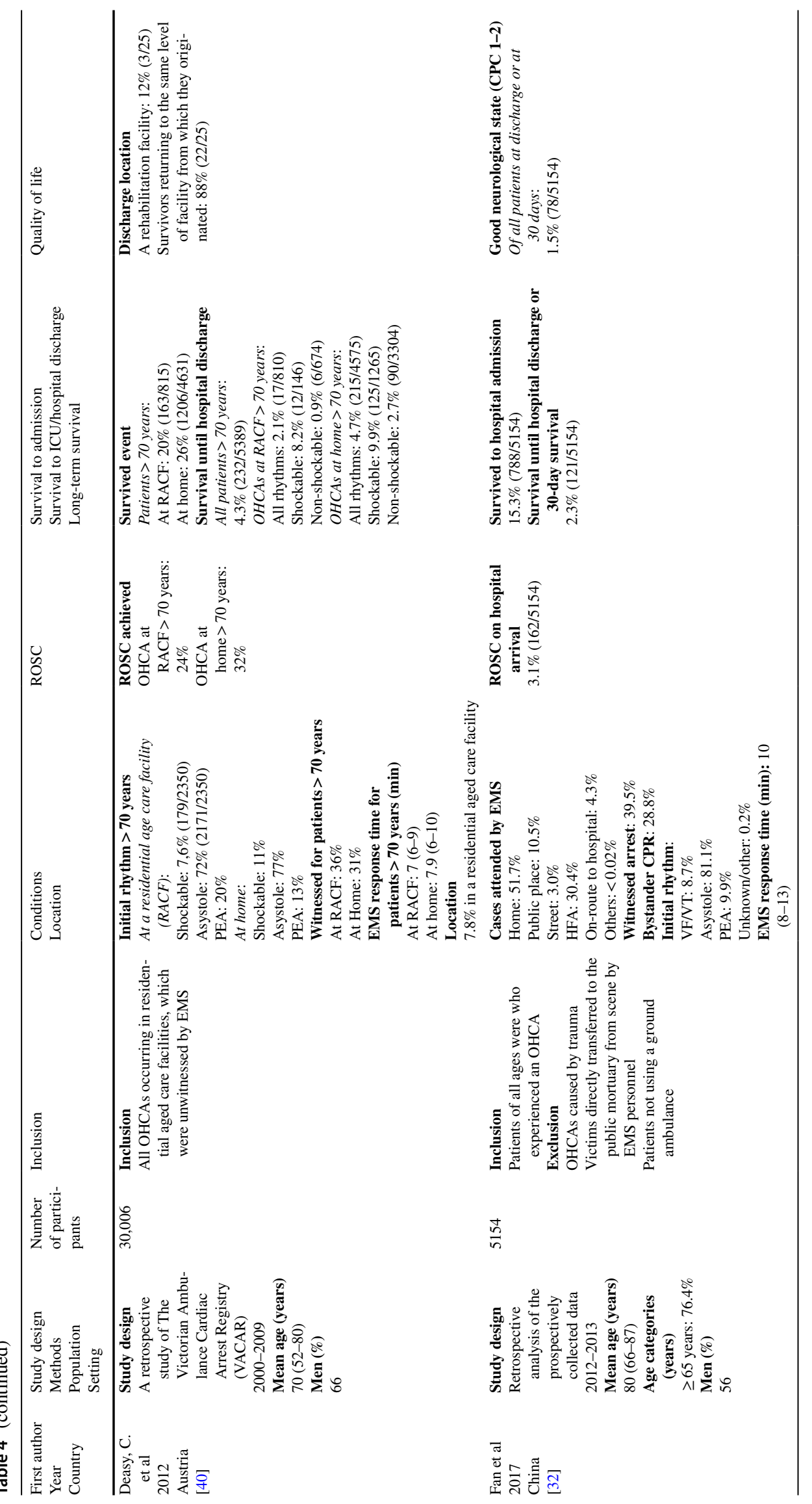




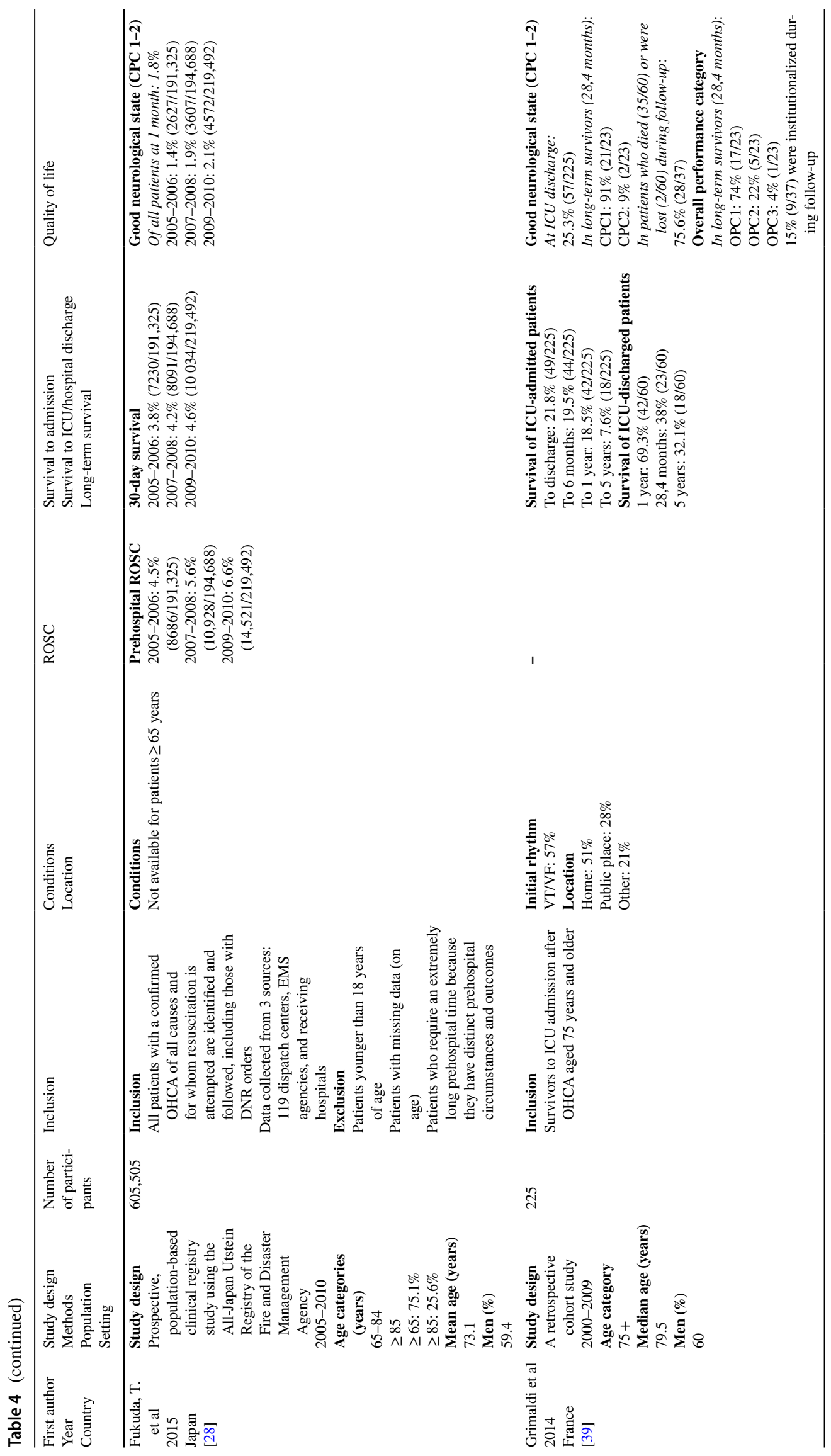




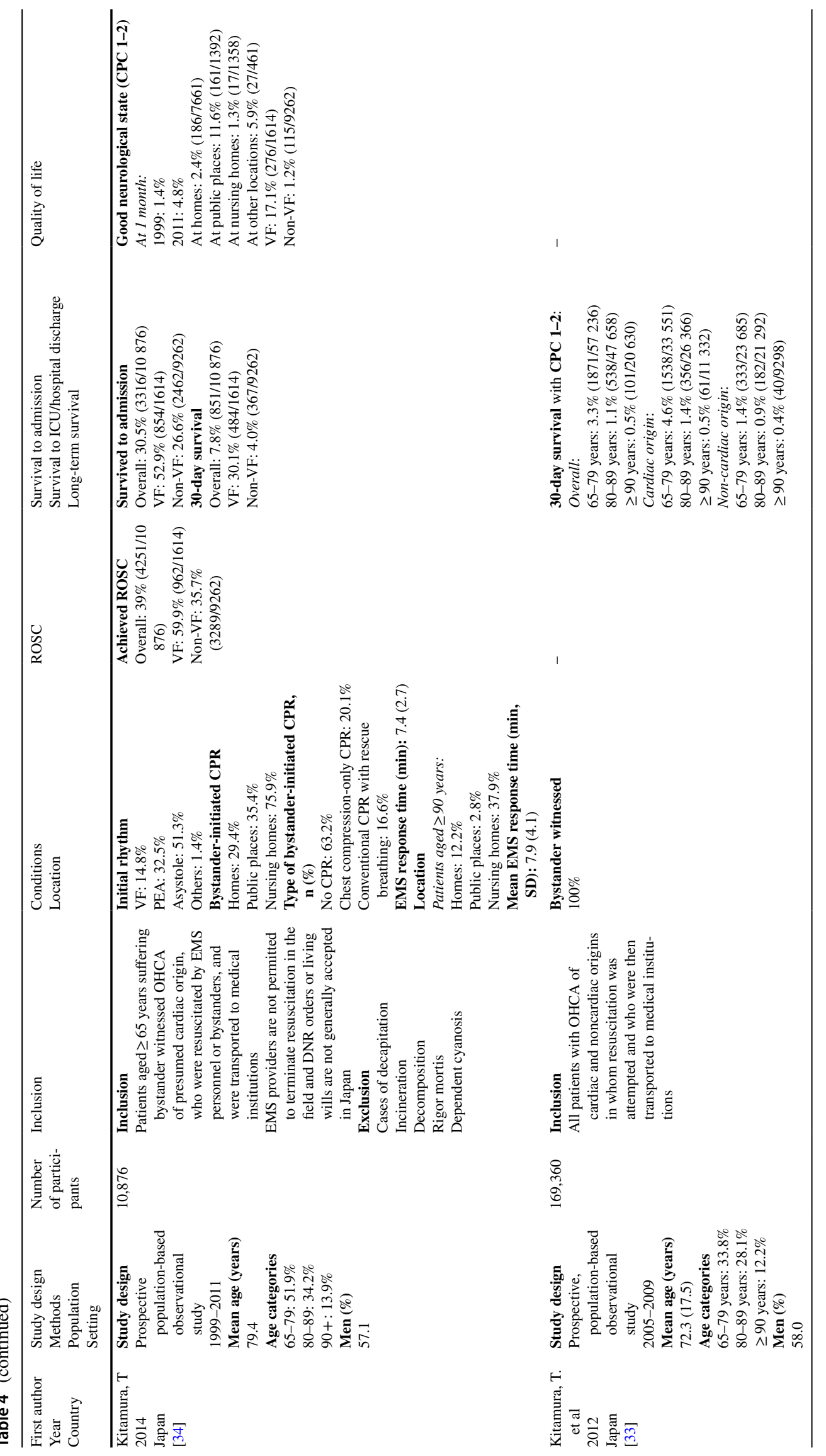




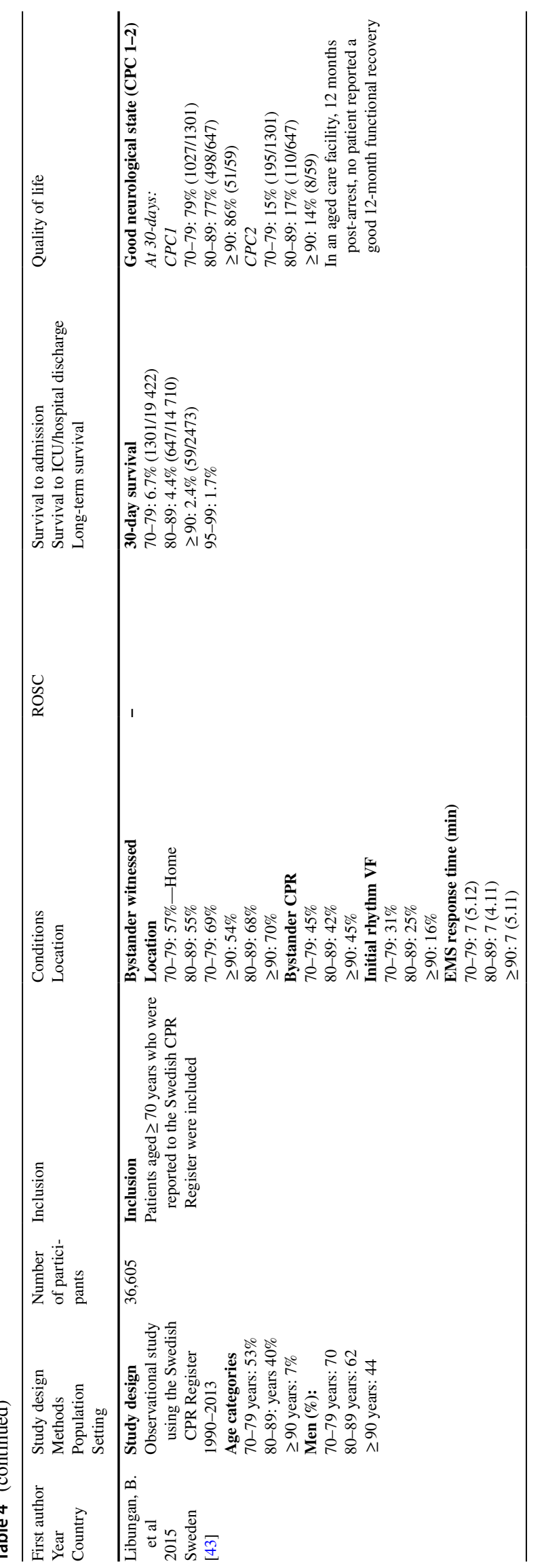




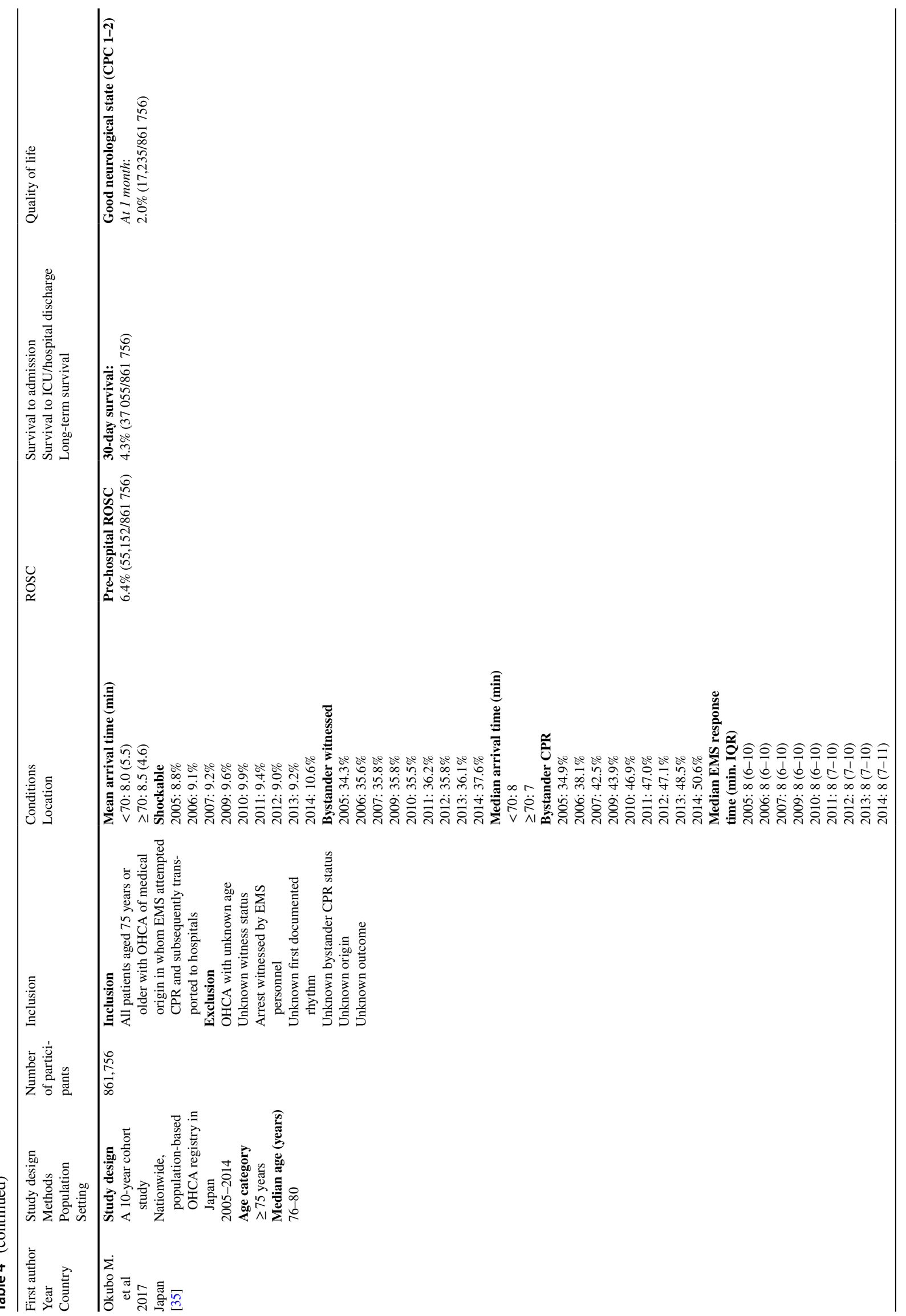




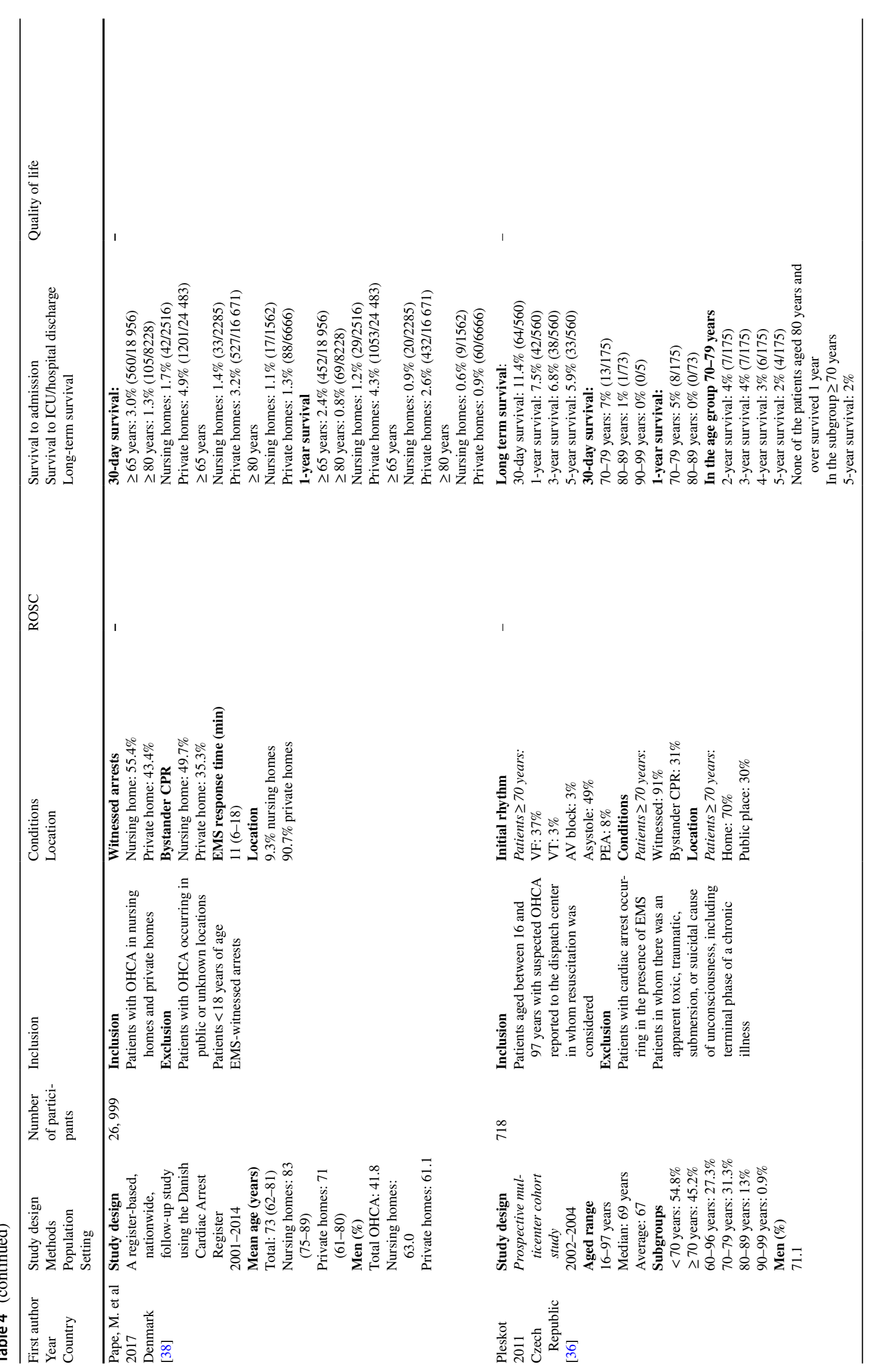




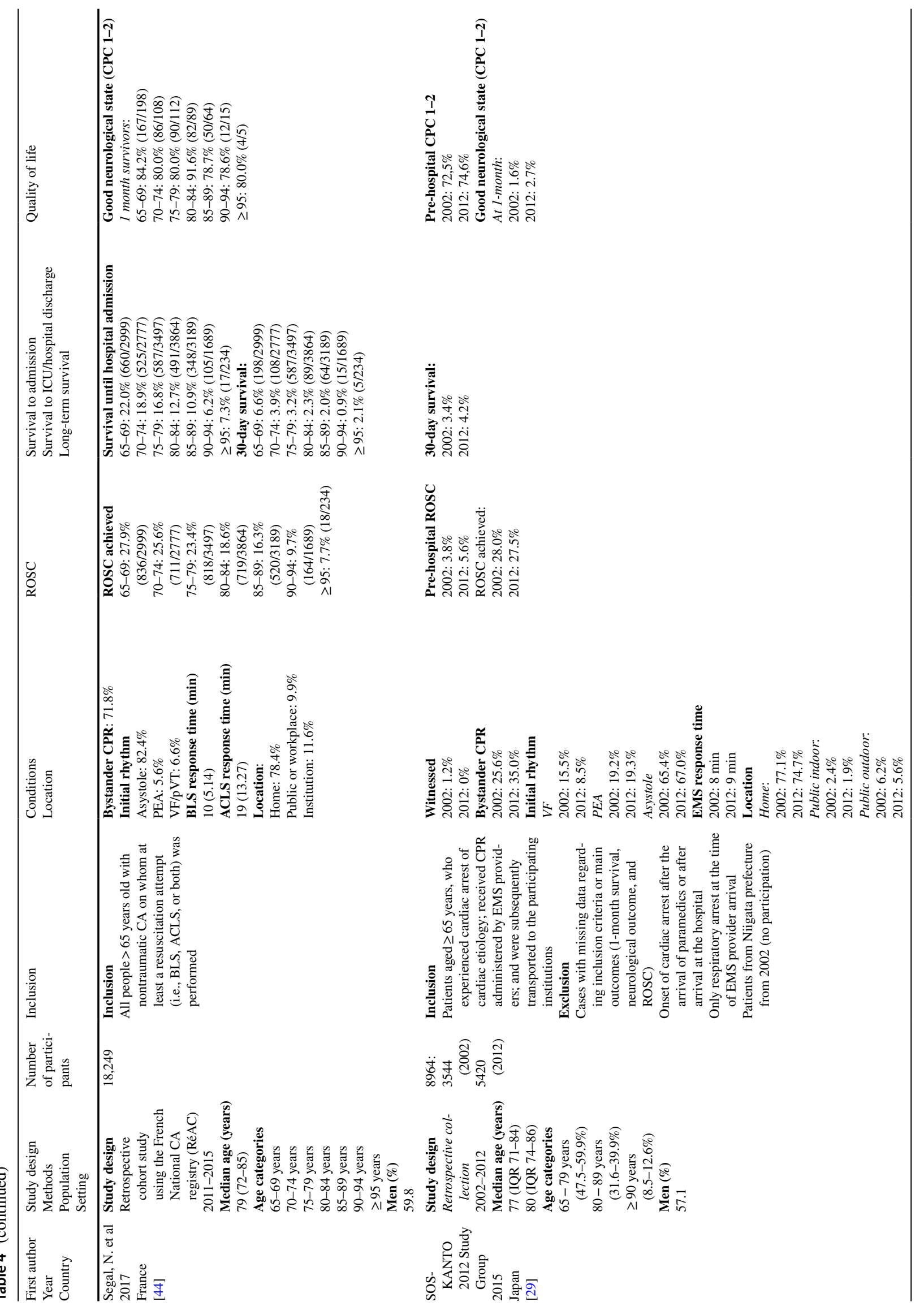




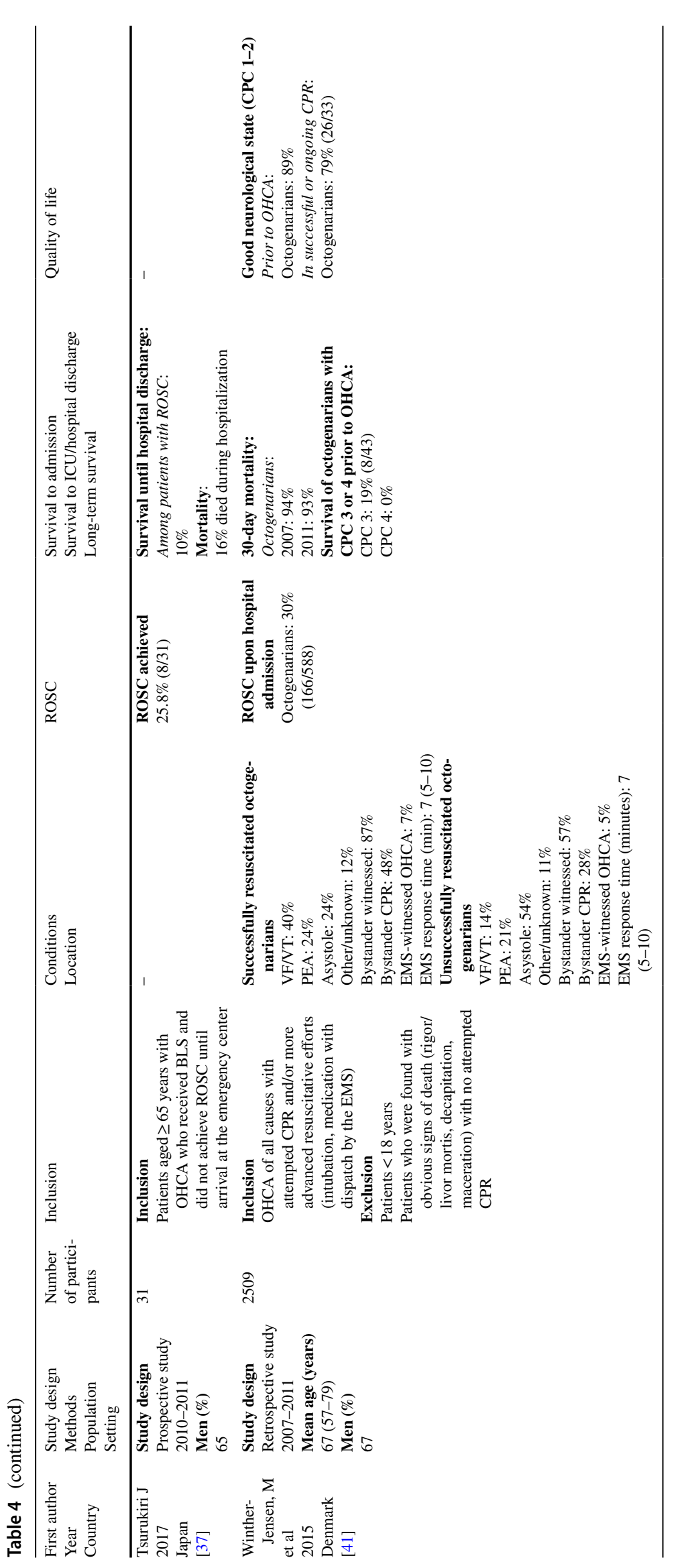


from 16 to $28.5 \%$ [28, 29]. Five studies registered an overall 1-month survival ranging from 13.5 to $28 \%[16,18,23,24$, 26]. Three studies found an overall 1-year survival between 9.4 and $25 \%[23,24,26]$.

The systematic review concerning OHCAs consisted of 23 studies. Four of these studies featured patients of 70 years and up exclusively, while five had a mean age of at least 70 years and the remaining studies provided various age categories. A meta-analysis for survival was performed on 14 studies. In patients aged 70 years or older, the overall survival until discharge was $4.1 \%$ (range 0-9\%). The probability of survival significantly decreased as age increased, both in univariate and multivariate analyses.

Survival until hospital admission registered in five primary studies was $15.3-30.5 \%$ [31, 32, 34, 44, 45]. The survival until hospital discharge was registered in nine additional studies was also slightly higher than the previously published review and varied from 6.9 to $11.1 \%$ [32, $35-37,42,44,45,47,50]$. Twelve studies registered the 1-month survival rate, ranging from 3.8 to $7.8 \%$ of all patients $[28,29,31-36,38,41,43,44]$. Of those who survived until hospital discharge, 1-year survival reached $88 \%$ [45]. Two studies found a 3-year survival rate ranging from 6.8 to $52.8 \%$ [31, 36]. Survival up to 5 years was also registered in two studies and ranged from 2 to $32.1 \%$ $[36,39]$.

\section{Neurological assessment}

The results of both the IHCA and OHCA reviews on quality of life following CPR were scarce and contradictory [14, 15].

In the primary IHCA studies exploring CPC as an outcome, a favorable outcome (CPC 1-2) was found in a mean of $20.1-23.6 \%$ of all resuscitated patients [16, 23]. This proved to be $82.4-93.1 \%$ of the patients surviving until hospital discharge $[16,23,26]$. In the primary OHCA studies, a CPC 1-2 at discharge or at 1 month was registered in only $1-4.8 \%$ of all resuscitated patients $[28,29,32,34,35]$. On the other hand, one study saw that of all survivors until hospital discharge aged 90 years or older, a favorable outcome at 1 month (CPC 1 or 2) was found in all patients (100\%) [43].

\section{Discharge location}

In the IHCA review, the discharge location was registered in only one of the included studies. Out of 50 patients who survived until hospital discharge, $38 \%$ were discharged to their homes, $24 \%$ were admitted to a rehabilitation or psychiatric facility, $18 \%$ to a nursing home and $20 \%$ were transferred to a chronic care hospital with ventilator capabilities [14]. The proportion of patients who returned home after hospital discharge was registered in three primary IHCA studies and three OHCA studies, ranging from 4.8 to $40 \%$ and $52.6-77.9 \%$, respectively $[17,19,26,27,31,39]$. Concerning one OHCA study, $88 \%$ returned to the same type of facility from which they originated [40].

\section{Functional recovery}

Furthermore, one study concerning IHCA found that although $74.9 \%$ of the survivors were functionally independent at hospital admission only $20.1 \%$ remained so after the event. In total, $63.4 \%$ of survivors were less functional upon hospital discharge compared to their state at the time of admission [17].

With regard to the OHCA cases, two studies used additional QoL measures such as the Overall Performance Category, SF-12 score, GOSE score, and the EQ-5D score $[27,39]$.The mean SF-12 mental component summary was 56.5 (SD 6.5). In contrast, the mean SF-12 physical component summary was 44.8 (SD 11.2), and this decreased with increasing age $(p<0.001)$. They found an upper and lower severe disability in $18.4 \%$ of the survivors, with the highest proportion in the age category 85 years and older (44.3\%) [27].

\section{Age categories}

See Table 5.

\section{Risk factors}

Nineteen studies analyzed risk factors associated with shortterm and long-term survivals following IHCA and OHCA [17-23, 26, 30-32, 36, 38-41, 43-45].

Patient-related factors associated with worse survival rates were increasing age, a previous history of heart failure or chronic obstructive pulmonary disease, malignancy, renal dysfunction, and multiorgan failure and/or septicemia after CPR. Pertaining OHCA, several studies found that increasing age was associated with worse survival outcomes, but a high Charlson Comorbidity Index (CCI $\geq 4)$ was not significantly associated with survival.

Arrest characteristics repeatedly associated with increased survival included: initial shockable rhythm (ventricular fibrillation and pulseless ventricular tachycardia), witnessed or ECG monitored arrests, cardiac etiology of arrest, monitored hospital location and time of arrest (during working hours on weekdays). The same risk factors were found concerning OHCA. In addition, arrests at public places were associated with increased survival rates, while arrests that occurred in nursing homes and multiple CPR events resulted in lower chances of survival. 
Finally, rescue characteristics such as bystander CPR/ defibrillation and shorter time to EMS response, defibrillation and ROSC were also associated with better survival outcomes following both IHCA and OHCA.

Eight studies analyzed risk factors associated with neurological and functional outcome following IHCA or OHCA. Increasing age was associated with worse functional outcomes, whereas initial shockable rhythm, cardiac etiology, public location of the arrest or witnessed arrest, and resuscitation factors such as bystander CPR, early EMS response and early use of automated external defibrillator were associated with a favorable neurological outcome $[27,28,33,34$, $42,45]$. In addition, being functionally dependent before hospital admission and an admission diagnosis of trauma were associated with less optimal functional outcomes [17, 18].

\section{Discussion}

This scoping review presents an overview of the survival and quality of life of older patients following IHCA or OHCA. Data regarding the last decennium indicate a slight improvement in the survival until hospital discharge rates at ages 70 years and older following IHCA. Van Gijn et al. (including articles from 1968 to 2012) found an overall survival until hospital discharge of $18.7 \%$ for patients between 70 and 79 years old, $15.4 \%$ for patients between 80 and 89 years old, and $11.6 \%$ for patients of 90 years and older, whereas in more recent primary studies (including articles from 2012 to 2018), these rates were consistently higher (19-28\%, $11.3-19 \%$ and $11-15 \%$, respectively). The same trend was noted for OHCA with an overall survival rate of $4.1 \%$ in the systematic review from 1980 to 2011 versus a survival rate of $4.3-12 \%$ in the primary studies from 2011 to 2018 , for patients aged 70 years or older.

Neurological outcome of resuscitated patients following IHCA or OHCA was only evaluated in a limited number of studies. Considering all resuscitated patients, the proportion that survived until hospital discharge with a favorable neurological outcome never exceeded $25 \%$. However, considering the subgroup of patients surviving until hospital discharge or 30 days, the proportion with a good neurological outcome was eminently high, namely $82-100 \%$ regardless of the age.

\section{Considerations}

Possibly partially responsible for these improved survival rates is the increased initiation of CPR and/or defibrillation by bystanders out-of-hospital. Better management of complications and post-resuscitation care in-hospital, a specific task of the geriatrician, could also be an important factor contributing to the improved outcomes [48]. However, favorable results are more often seen following cardiac arrests with shockable rhythms which are only present in a minority of the older population. Consequently, overall survival rates remain low.

The effect of age on outcome remains controversial. While the included systematic reviews found that old age was associated with worsened survival outcomes for both IHCA and OHCA, other previously published studies could not find any association [49-51]. These inconsistent results may partially be explained by differences in patient characteristics, circumstances of the cardiac arrest, post-resuscitation care, cultural practices, do-not-attempt resuscitation policies, and withdrawal of life-sustaining treatment practice [52]. Moreover, the older population is particularly heterogeneous. The prevalence of multi-morbidity is increasing from 35 to $65 \%$ in patients aged $60-69$ years to $80-99 \%$ in octogenarians [53]. In addition, the reduction of the physiological reserve of multiple organ systems with aging, called frailty, results in an increased inability to maintain homeostasis when faced with disease or injury. As such, not chronological age, but the level of frailty, which results in the reduced ability to withstand acute stress situations such as cardiac arrests, may be an important contributing factor for worse

Table 5 Results categorized by age

\begin{tabular}{llll}
\hline & $70-79$ years & $80-89$ years & $\geq 90$ years \\
\hline IHCA & & & $11-15.1 \%[18,19]$ \\
Survival until discharge & $20.1-27.9 \%[18,19,26]$ & $15.3-21.5 \%[18,19,26]$ & $14 \%[18]$ \\
One-month survival & $27.9 \%[18]$ & $20 \%[18]$ & $11.5 \%[18]$ \\
CPC 1-2 at discharge & $22.7 \%[18]$ & $16.5 \%[18]$ & $\geq 90$ years \\
& $\geq 70$ years & & \\
OHCA & & $2.8-8 \%[30,45]$ & $1.7-3.9 \%[42]$ \\
Survival until discharge & $4.3-12.0 \%[30,40,45]$ & $0.9-7 \%[36,38,41,43,44]$ & $0-2.4 \%[36,43,44]$ \\
One-month survival & $5.4-5.7 \%[36,43,44]$ & $0.9 \%[33]$ & $0.5-1.8 \%[28,33]$ \\
CPC 1-2 at discharge/1-month & $10.5 \%[44]$ & $0-6 \%[36,38,45]$ & $0 \%[36]$ \\
One-year survival & $3.2-10 \%[36,45]$ & \\
\hline
\end{tabular}


survival outcomes [3]. This was confirmed by a recent study published after this review [54]. These results may facilitate clinical decision making regarding whether CPR may be considered futile.

In conclusion, age alone should not be used as the sole criterium to decide whether CPR is a medically appropriate treatment for the older patient. Patient-related factors (age, medical history and frailty), arrest characteristics (initial rhythm, witnessed of monitored, etiology, location and time) and rescue characteristics (bystander CPR/defibrillation and shorter time to EMS response, defibrillation and ROSC) should also be taken into account.

\section{Strengths and limitations}

Strengths of this study include giving a comprehensive overview of the most recent available data on outcomes concerning survival, neurological state and quality of life of both in-hospital and out-of-hospital CPR in older patients, by systematically including return of spontaneous circulation (ROSC), survival until hospital discharge, long-term survival ( $\geq 1$ year following the event), discharge location and other quality of life measurements as outcome variables.

This review has several limitations, due to the heterogeneity of classification in the individual studies we were not able to compare outcomes of specific age categories. The age categories were randomly selected, making comparison of outcomes between studies impractical. As a result, no meta-analysis was performed. However, no tools were used to measure the heterogeneity in this review. Furthermore, the pooled odds ratios concerning the risk factors were also not calculated in this study.

In addition, as a result of the inclusion of studies from various regions, different views and regulations concerning CPR performance have been adopted. For example, EMS providers in Japan are not permitted to terminate resuscitation in the field (except in case of decapitation or dissolution), and Do-Not-Resuscitate (DNR) orders are not generally accepted. Therefore, the generalisability of these study results is restricted.

Moreover, the term 'frailty' was only mentioned in one study concerning IHCAs [20]. Four OHCA studies mentioned frailty, but did not include this variable in their analysis. This would, however, allow healthcare providers to better differentiate older patients with poor prognosis from those with a good chance of survival. A multidimensional interdisciplinary diagnostic process is required to determine an older person's medical, psychological and functional capability, such as a comprehensive geriatric assessment. The Clinical Frailty Scale is also a simple bedside assessment that can provide invaluable information when considering treatment escalation plans [54].
Finally, it is also possible that some eligible studies were missed because they did not specifically refer to older patients in the title or abstract. However, by performing an elaborate search and thorough cross-referencing, this risk was reduced to a minimum.

\section{Implication for practice}

The review provides an overview of the recent evidence on outcome regarding survival and quality of life after CPR following both IHCA and OHCA in the older population. CPR for patients of advanced age should be seen as a conditional therapy that may be worthwhile in some older patients, but may cause significant harm and suffering when applied in an undifferentiated way [55]. This knowledge can contribute to end-of-life conversations between health care practitioner and patient to make well-informed decisions and promote advance care planning (ACP). In hospitalized, frail or elderly patients, the etiology of the arrests is more likely to be complex due to other pathologies and complications [56]. These patients should be well informed about the overall low chance of survival and a significant possibility of neurological deficits, especially for nursing home residents. On the other hand, all patients with a limited risk profile should be informed of their chances of survival with a good neurological outcome following CPR [57].

Advance care planning in the hospital and in longterm-care facilities such as nursing homes can help avoid unwanted or ill-advised CPR. Results show that the implementation of ACP possibly decreases potentially inappropriate life-sustaining treatment, increases the use of hospice and palliative care and prevents hospitalization. It has also proven useful to include end-of-life choices such as Do-NotResuscitate decisions [55, 58].

When cardiac arrests happen outside the hospital, information about possible advance care planning is generally unavailable. Validated rules for prehospital termination of resuscitation (TOR) could be highly valuable in such cases to avoid futile transport and escalation of care. Until now, there is no international agreement on TOR rules neither on how to apply them. Verbeek et al. and Morrison LJ et al. propose the following criteria: arrest unwitnessed by EMS provider, no shock delivered, no prehospital ROSC, unwitnessed by bystander or no bystander CPR in an Advanced Life Support setting [59, 60]. Shibahashi et al. propose the following three criteria: non-shockable initial rhythm, unwitnessed by bystanders, and age $\geq 73$ years; this TOR rule provided an excellent positive predictive value ( $>99 \%$ ) for unfavorable 1-month neurological outcome after OHCA [61]. These criteria were validated in North America by Grunau and Glober [62, 63]. 


\section{Future research}

None of the included studies was able to capture a good image of the patients' quality of life broader than the neurological outcome. Most of the studies merely used the CPC scale which is insufficiently attuned to identifying all the impairments of cardiac arrest survivors [46]. In addition, this score excludes return to private homes, participation in society or other aspects of life greatly valued by this category of patients such as the desire to avoid being a burden to their family, suffering pain, the loss of speech, the loss of dignity and the incapacity to think clearly [64]. Only two studies incorporated multiple measurement tools to assess the quality of life, namely the Extended Glasgow Outcome Score (or GOSE), the Overall Performance Category (OPC), the SF-12 score, and the EQ-5D score [27, 29]. More extensive research into quality of life after resuscitation will allow patients to make better-informed decisions and facilitate decision making adopted to the patient's clinical situation.

A core outcome set for cardiac arrest (COSCA) was recently developed for adults that identified survival, neurological function, and health-related quality of life as essential outcomes in cardiac arrest effectiveness trials. They stated that survival until hospital discharge, at 30 days, or both should be reported, accompanied by neurological state. Health-related quality of life should be measured with $\geq 1$ tools from the Health Utilities Index-3 questionnaires, Short Form Health survey 36 version 2 or the five-level EQ-5D instruments at 90 days and at periodic intervals up to 1 year after cardiac arrest, if resources allow [65, 66]. Further research should implement this assessment method and determine if it is also optimal for evaluation of the older population. Prospective study designs are preferred, because many potentially relevant prearrest factors or outcome measures cannot be retrieved retrospectively.

\section{Conclusion}

Hospital survival rates following IHCA and OHCA in the older population improved in the recent decade, though do not exceed $28.5 \%$ and $11.1 \%$, respectively. Several risk factors were identified, among which increasing age and nursing home residency. However, the effect of age on outcome remains controversial and age should not be used as the sole decision criterium whether to initiate CPR. Future research should analyze frailty as an independent variable regardless of age and include more extensive quality of life measures as outcome variables.

Supplementary Information The online version contains supplementary material available at https://doi.org/10.1007/s41999-021-00454-y.

\section{Compliance with ethical standards}

Conflict of interest On behalf of all the authors, the corresponding author states that there is no conflict of interest.

\section{References}

1. Jacobs I, Nadkarni V, Bahr J, Berg RA, Billi JE, Bossaert L et al (2004) Cardiac arrest and cardiopulmonary resuscitation outcome reports: update and simplification of the Utstein templates for resuscitation registries. A statement for healthcare professionals from a task force of the international liaison committee on resuscitation (American Heart Association, European Resuscitation Council, Australian Resuscitation Council, New Zealand Resuscitation Council, Heart and Stroke Foundation of Canada, InterAmerican Heart Foundation, Resuscitation Council of Southern Africa). Resuscitation 63(3):233-249 (PubMed PMID: 15582757. Epub 2004/12/08. eng)

2. Matsuyama T, Kitamura T, Kiyohara K, Kiguchi T, Kobayashi D, Nishiyama C et al (2018) Assessment of the 11-year nationwide trend of out-of-hospital cardiac arrest cases among elderly patients in Japan (2005-2015). Resuscitation 131:83-90 (PubMed PMID: 30099119. Epub 2018/08/14.eng)

3. Tarras SL, Napolitano LM (2017) Critical Care Epidemiology and Outcomes/Resource Use in the Elderly. In: Luchette FA, Yelon JA (eds) Geriatric trauma and critical care. Springer International Publishing, Cham, pp 355-366

4. Neumar RW, Nolan JP, Adrie C, Aibiki M, Berg RA, Bottiger BW et al (2008) Post-cardiac arrest syndrome: epidemiology, pathophysiology, treatment, and prognostication. A consensus statement from the International Liaison Committee on Resuscitation (American Heart Association, Australian and New Zealand Council on Resuscitation, European Resuscitation Council, Heart and Stroke Foundation of Canada, InterAmerican Heart Foundation, Resuscitation Council of Asia, and the Resuscitation Council of Southern Africa); the American Heart Association Emergency Cardiovascular Care Committee; the Council on Cardiovascular Surgery and Anesthesia; the Council on Cardiopulmonary, Perioperative, and Critical Care; the Council on Clinical Cardiology; and the Stroke Council. Circulation 118(23):2452-83 (PubMed PMID: 18948368. Epub 2008/10/25.eng)

5. Kim J-H, Oh Ym, So BH, Hong TY, Lee WJ, Choi SP et al (2008) Systemic complications of comatose survivors following cardiopulmonary resuscitation

6. Mongardon N, Dumas F, Ricome S, Grimaldi D, Hissem T, Pene F et al (2011) Postcardiac arrest syndrome: from immediate resuscitation to long-term outcome. Annals of intensive care 1(1):45 (PubMed PMID: 22053891; PMCID: PMC3223497. Epub 2011/11/08.eng)

7. Heyland DK, Barwich D, Pichora D, Dodek P, Lamontagne F, You JJ et al (2013) Failure to engage hospitalized elderly patients and their families in advance care planning. JAMA Intern Med 173(9):778-787 (PubMed PMID: 23545563. Epub 2013/04/03. eng)

8. Heyland DK, Dodek P, Rocker G, Groll D, Gafni A, Pichora D et al (2006) What matters most in end-of-life care: perceptions of seriously ill patients and their family members. Cmaj 174(5):627633 (PubMed PMID: 16505458; PMCID: PMC1389825. Epub 2006/03/01.eng)

9. Philippart F, Vesin A, Bruel C, Kpodji A, Durand-Gasselin B, Garcon P et al (2013) The ETHICA study (part I): elderly's thoughts about intensive care unit admission for life-sustaining 
treatments. Intensive Care Med 39(9):1565-1573 (PubMed PMID: 23765236. Epub 2013/06/15.eng)

10. Murphy DJ, Burrows D, Santilli S, Kemp AW, Tenner S, Kreling B et al (1994) The influence of the probability of survival on patients' preferences regarding cardiopulmonary resuscitation. $\mathrm{N}$ Engl J Med 330(8):545-549 (PubMed PMID: 8302322. Epub 1994/02/24.eng)

11. Chang WH, Huang CH, Chien DK, Su YJ, Lin PC, Tsai CH (2009) Factors analysis of cardiopulmonary resuscitation outcomes in the elderly in Taiwan. Int J Gerontol 3(1):16-25 (English)

12. Chamberlain D (2010) Predictors of survival from out-of-hospital cardiac arrest. Heart 96(22):1785-1786 (PubMed PMID: 20965991. Epub 2010/10/23.eng)

13. Narang AT, Sikka R (2006) Resuscitation of the elderly. Emerg Med Clin North Am 24(2):261-272 (PubMed PMID: 16584957. Epub 2006/04/06.eng)

14. van Gijn MS, Frijns D, van de Glind EM, B CvM, Hamaker ME (2014) The chance of survival and the functional outcome after in-hospital cardiopulmonary resuscitation in older people: a systematic review. Age Ageing 43(4):456-463 (PubMed PMID: 24760957. Epub 2014/04/25.eng)

15. van de Glind EM, van Munster BC, van de Wetering FT, van Delden JJ, Scholten RJ, Hooft L (2013) Pre-arrest predictors of survival after resuscitation from out-of-hospital cardiac arrest in the elderly a systematic review. BMC Geriatr 13:68 (English)

16. Al-Dury N, Rawshani A, Israelsson J, Stromsoe A, Aune S, Agerstrom J et al (2017) Characteristics and outcome among 14,933 adult cases of in-hospital cardiac arrest: A nationwide study with the emphasis on gender and age. Am J Emerg Med 35(12):18391844 (PubMed PMID: 28624147. Epub 2017/06/19.eng)

17. Gershengorn HB, Li G, Kramer A, Wunsch H (2012) Survival and functional outcomes after cardiopulmonary resuscitation in the intensive care unit. J Crit Care 27(4):421.e9-17 (PubMed PMID: 22227081. Epub 2012/01/10.eng)

18. Hirlekar G, Karlsson T, Aune S, Ravn-Fischer A, Albertsson P, Herlitz J et al (2017) Survival and neurological outcome in the elderly after in-hospital cardiac arrest. Resuscitation 118:101-106 (PubMed PMID: 28736324. Epub 2017/07/25.eng)

19. Menon PR, Ehlenbach WJ, Ford DW, Stapleton RD (2014) Multiple in-hospital resuscitation efforts in the elderly. Critical Care Med 42(1):108-117 (PubMed PMID: 24346518; PMCID: PMC3867742. Epub 2013/12/19.eng)

20. Roedl K, Jarczak D, Becker S, Fuhrmann V, Kluge S, Muller J (2018) Long-term neurological outcomes in patients aged over 90 years who are admitted to the intensive care unit following cardiac arrest. Resuscitation 132:6-12 (PubMed PMID: 30144464. Epub 2018/08/26.eng)

21. Chan PS, Berg RA, Spertus JA, Schwamm LH, Bhatt DL, Fonarow GC et al (2013) Risk-standardizing survival for in-hospital cardiac arrest to facilitate hospital comparisons. J Am Coll Cardiol 62(7):601-609 (PubMed PMID: 23770167; PMCID: PMC3769937. Epub 2013/06/19.eng)

22. DeVoe B, Roth A, Maurer G, Tamuz M, Lesser M, Pekmezaris $\mathrm{R}$ et al (2016) Correlation of the predictive ability of early warning metrics and mortality for cardiac arrest patients receiving in-hospital Advanced Cardiovascular Life Support. Heart Lung 45(6):497-502 (PubMed PMID: 27697395. Epub 2016/10/05. eng)

23. Hessulf F, Karlsson T, Lundgren P, Aune S, Strömsöe A, Södersved Källestedt ML et al (2018) Factors of importance to 30-day survival after in-hospital cardiac arrest in Sweden-a population-based register study of more than 18,000 cases. Int J Cardiol 255:237-242 (English)

24. Thompson LE, Chan PS, Tang F, Nallamothu BK, Girotra S, Perman SM et al (2018) Long-term survival trends of medicare patients after in-hospital cardiac arrest: insights from get with the guidelines-resuscitation ${ }^{\circledR}$. Resuscitation 123:58-64 (English)

25. Kazaure HS, Roman SA, Sosa JA (2013) Epidemiology and outcomes of in-hospital cardiopulmonary resuscitation in the United States, 2000-2009. Resuscitation 84(9):1255-1260 (PubMed PMID: 23470471. Epub 2013/03/09.eng)

26. Chan PS, Nallamothu BK, Krumholz HM, Spertus JA, Li Y, Hammill BG et al (2013) Long-term outcomes in elderly survivors of in-hospital cardiac arrest. N Engl J Med 368(11):1019-1026 (PubMed PMID: 23484828 (PMCID: PMC3652256. Epub 2013/03/15.eng)

27. Andrew E, Mercier E, Nehme Z, Bernard S, Smith K (2018) Long-term functional recovery and health-related quality of life of elderly out-of-hospital cardiac arrest survivors. Resuscitation 126:118-124 (PubMed PMID: 29545136. Epub 2018/03/17. eng)

28. Fukuda T, Ohashi-Fukuda N, Matsubara T, Doi K, Kitsuta Y, Nakajima $S$ et al (2015) Trends in Outcomes for Out-of-Hospital Cardiac Arrest by Age in Japan: An Observational Study. Medicine (Baltimore) 94(49):e2049 (PubMed PMID: 26656330 (PMCID: PMC5008475. Epub 2015/12/15.eng)

29. Group S-KS (2015) Changes in treatments and outcomes among elderly patients with out-of-hospital cardiac arrest between 2002 and 2012: a post hoc analysis of the SOS-KANTO 2002 and 2012. Resuscitation 97:76-82 (PubMed PMID: 26410571. Epub 2015/09/28.eng)

30. Abrams HC, Moyer PH, Dyer KS (2011) A model of survival from out-of-hospital cardiac arrest using the Boston EMS arrest registry. Resuscitation 82(8):999-1003 (PubMed PMID: 21546147. Epub 2011/05/07.eng)

31. Chan PS, McNally B, Nallamothu BK, Tang F, Hammill BG, Spertus JA et al (2016) Long-term outcomes among elderly survivors of out-of-hospital cardiac arrest. J Am Heart Assoc 5(3):e002924 (PubMed PMID: 27068632 (PMCID: PMC4943267. Epub 2016/04/14.eng)

32. Fan KL, Leung LP, Siu YC (2017) Out-of-hospital cardiac arrest in Hong Kong: a territory-wide study. Hong Kong Med J 23(1):48-53 (PubMed PMID: 28057896. Epub 2017/01/07.eng)

33. Kitamura T, Iwami T, Kawamura T, Nitta M, Nagao K, Nonogi $\mathrm{H}$ et al (2012) Nationwide improvements in survival from out-ofhospital cardiac arrest in Japan. Circulation 126(24):2834-2843 (PubMed PMID: 23035209. Epub 2012/10/05.eng)

34. Kitamura T, Morita S, Kiyohara K, Nishiyama C, Kajino K, Sakai $T$ et al (2014) Trends in survival among elderly patients with outof-hospital cardiac arrest: a prospective, population-based observation from 1999 to 2011 in Osaka. Resuscitation 85(11):14321438 (PubMed PMID: 25110248. Epub 2014/08/12.eng)

35. Okubo M, Kiyohara K, Iwami T, Callaway CW, Kitamura T (2017) Nationwide and regional trends in survival from out-ofhospital cardiac arrest in Japan: A 10-year cohort study from 2005 to 2014. Resuscitation 115:120-128 (PubMed PMID: 28392371. Epub 2017/04/11.eng)

36. Pleskot M, Hazukova R, Stritecka H, Cermakova E (2011) Fiveyear survival of patients after out-of-hospital cardiac arrest depending on age. Arch Gerontol Geriatr 53(2):e88-e92 (PubMed PMID: 20678813. Epub 2010/08/04.eng)

37. Tsurukiri J, Nagata K, Kumasaka K, Ueno K, Ueno M (2017) Middle latency auditory evoked potential index for prediction of postresuscitation survival in elderly populations with out-of-hospital cardiac arrest. Signa Vitae 13(1):80-3 (English)

38. Pape M, Rajan S, Hansen SM, Mortensen RN, Riddersholm S, Folke F et al (2018) Survival after out-of-hospital cardiac arrest in nursing homes - a nationwide study. Resuscitation 125:90-98 (English)

39. Grimaldi D, Dumas F, Perier MC, Charpentier J, Varenne O, Zuber $B$ et al (2014) Short- and long-term outcome in elderly patients after out-of-hospital cardiac arrest: a cohort study. Crit Care Med 
42(11):2350-2357 (PubMed PMID: 25054671. Epub 2014/07/24. eng)

40. Deasy C, Bray JE, Smith K, Harriss LR, Bernard SA, Davidson PM et al (2012) Resuscitation of out-of-hospital cardiac arrests in residential aged care facilities in Melbourne, Australia. Resuscitation 83(1):58-62 (PubMed PMID: 21756967. Epub 2011/07/16.eng)

41. Winther-Jensen M, Kjaergaard J, Hassager C, Bro-Jeppesen J, Nielsen N, Lippert FK et al (2015) Resuscitation and post resuscitation care of the very old after out-of-hospital cardiac arrest is worthwhile. Int J Cardiol 201:616-623 (English)

42. Andersen LW, Bivens MJ, Giberson T, Giberson B, Mottley JL, Gautam S et al (2015) The relationship between age and outcome in out-of-hospital cardiac arrest patients. Resuscitation 94:49-54 (PubMed PMID: 26044753. Epub 2015/06/06.eng)

43. Libungan B, Lindqvist J, Stromsoe A, Nordberg P, Hollenberg J, Albertsson P et al (2015) Out-of-hospital cardiac arrest in the elderly: A large-scale population-based study. Resuscitation 94:28 32 (PubMed PMID: 26073274. Epub 2015/06/16.eng)

44. Segal N, di Pompeo C, Escutnaire J, Wiel E, Dumont C, Castra L et al (2018) Evolution of survival in cardiac arrest with age in elderly patients: Is resuscitation a dead end? J Emerg Med 54(3):295-301 (PubMed PMID: 29273461. Epub 2017/12/24.eng)

45. Beesems SG, Blom MT, van der Pas MH, Hulleman M, van de Glind EM, van Munster BC et al (2015) Comorbidity and favorable neurologic outcome after out-of-hospital cardiac arrest in patients of 70 years and older. Resuscitation 94:33-39 (PubMed PMID: 26116780. Epub 2015/06/28.eng)

46. Ohlsson MA, Kennedy LM, Ebell MH, Juhlin T, Melander O (2016) Validation of the good outcome following attempted resuscitation score on in-hospital cardiac arrest in southern Sweden. Int J Cardiol 221:294-297 (PubMed PMID: 27404694. Epub 2016/07/13.eng)

47. Grenvik AS (1981) Brain failure and resuscitation. Churchill Livingstone, New York, pp 239-259

48. Buick JE, Drennan IR, Scales DC, Brooks SC, Byers A, Cheskes S et al (2018) Improving temporal trends in survival and neurological outcomes after out-of-hospital cardiac arrest. Circ Cardiovasc Qual Outcomes 11(1):e003561 (PubMed PMID: 29317455 (PMCID: PMC5791528. Epub 2018/01/11.eng)

49. Brindley PG, Markland DM, Mayers I, Kutsogiannis DJ (2002) Predictors of survival following in-hospital adult cardiopulmonary resuscitation. Can Med Assoc J 167(4):343-348

50. Bedell SE, Delbanco TL, Cook EF, Epstein FH (1983) Survival after cardiopulmonary resuscitation in the hospital. N Engl J Med 309(10):569-576 (PubMed PMID: 6877286. Epub 1983/09/08. eng)

51. Sandroni C, Ferro G, Santangelo S, Tortora F, Mistura L, Cavallaro $F$ et al (2004) In-hospital cardiac arrest: survival depends mainly on the effectiveness of the emergency response. Resuscitation 62(3):291-7 (PubMed PMID: 15325448. Epub 2004/08/25.eng)

52. Root ED, Gonzales L, Persse DE, Hinchey PR, McNally B, Sasson C (2013) A tale of two cities: the role of neighborhood socioeconomic status in spatial clustering of bystander CPR in Austin and Houston. Resuscitation 84(6):752-759 (PubMed PMID: 23318916 (PMCID: PMC3762246. Epub 2013/01/16.eng)

53. Buurman BM, Frenkel WJ, Abu-Hanna A, Parlevliet JL, de Rooij SE (2016) Acute and chronic diseases as part of multimorbidity in acutely hospitalized older patients. Eur J Intern Med 27:68-75 (PubMed PMID: 26477016. Epub 2015/10/20.eng)

54. Ibitoye SE, Rawlinson S, Cavanagh A, Phillips V, Shipway DJH (2020) Frailty status predicts futility of cardiopulmonary resuscitation in older adults. Age Ageing. https://doi.org/10.1093/ageing/ afaa104

55. Andersen LW, Holmberg MJ, Berg KM, Donnino MW, Granfeldt A (2019) In-hospital cardiac arrest: a review. JAMA 321(12):12001210 (PubMed PMID: 30912843. Epub 2019/03/27.eng)
56. Druwé P, Benoit DD, Monsieurs KG, Gagg J, Nakahara S, Alpert EA et al (2020) Cardiopulmonary resuscitation in adults over 80: outcome and the perception of appropriateness by clinicians. $\mathrm{J}$ Am Geriatr Soc 68(1):39-45 (PubMed PMID: 31840239. Epub 2019/12/17.eng)

57. Brinkman-Stoppelenburg A, Rietjens JA, van der Heide A (2014) The effects of advance care planning on end-of-life care: a systematic review. Palliat Med 28(8):1000-1025

58. Fan SY, Wang YW, Lin IM (2018) Allow natural death versus donot-resuscitate: titles, information contents, outcomes, and the considerations related to do-not-resuscitate decision. BMC Palliat Care 17(1):114

59. Verbeek PR, Vermeulen MJ, Ali FH, Messenger DW, Summers J, Morrison LJ (2002) Derivation of a termination-of-resuscitation guideline for emergency medical technicians using automated external defibrillators. Acad Emerg Med 9(7):671-8 (PubMed PMID: 12093706. Epub 2002/07/03.eng)

60. Morrison LJ, Verbeek PR, Vermeulen MJ, Kiss A, Allan KS, Nesbitt $L$ et al (2007) Derivation and evaluation of a termination of resuscitation clinical prediction rule for advanced life support providers. Resuscitation 74(2):266-275 (PubMed PMID: 17383072. Epub 2007/03/27.eng)

61. Shibahashi K, Sugiyama K, Hamabe Y (2018) A potential termination of resuscitation rule for EMS to implement in the field for out-of-hospital cardiac arrest: an observational cohort study. Resuscitation 130:28-32 (PubMed PMID: 29940294. Epub 2018/06/26. eng)

62. Glober NK, Tainter CR, Abramson TM, Staats K, Gilbert G, Kim D (2019) A simple decision rule predicts futile resuscitation of out-ofhospital cardiac arrest. Resuscitation 142:8-13 (PubMed PMID: 31228547. Epub 2019/06/23.eng)

63. Reynolds JC, Grunau BE, Rittenberger JC, Sawyer KN, Kurz MC, Callaway CW (2016) Association between duration of resuscitation and favorable outcome after out-of-hospital cardiac arrest: implications for prolonging or terminating resuscitation. Circulation 134(25):2084-2094 (PubMed PMID: 27760796; PMCID: PMC5173423. Epub 2016/10/21.eng)

64. Mead GE, O'Keeffe ST, Jack CI, Maestri-Banks AM, Playfer JR, Lye M (1995) What factors influence patient preferences regarding cardiopulmonary resuscitation? J R Coll Phys Lond 29(4):295-8 (PubMed PMID: 7473323; PMCID: PMC5401318. Epub 1995/07/01.eng)

65. Haywood K, Whitehead L, Nadkarni VM, Achana F, Beesems S, Bottiger BW et al (2018) COSCA (Core Outcome Set for Cardiac Arrest) in adults: an advisory statement from the international liaison committee on resuscitation. Resuscitation 127:147-163 (PubMed PMID: 29706235. Epub 2018/05/01.eng)

66. Haywood KL, Whitehead L, Perkins GD (2019) An international, consensus-derived Core Outcome Set for Cardiac Arrest effectiveness trials: the COSCA initiative. Curr Opin Crit Care 25(3):226233 (PubMed PMID: 30925524. Epub 2019/03/30.eng)

Publisher's Note Springer Nature remains neutral with regard to jurisdictional claims in published maps and institutional affiliations. 